\title{
On the Action of the Anti-Absence Drug Ethosuximide in the Rat and Cat Thalamus
}

\author{
Nathalie Leresche, ${ }^{2}$ H. Rheinallt Parri, ${ }^{1}$ Gül Erdemli, ${ }^{1}$ Alice Guyon, ${ }^{2}$ Jonathan P. Turner, ${ }^{1}$ \\ Stephen R. Williams, ${ }^{1}$ Eftihia Asprodini, ${ }^{1}$ and Vincenzo Crunelli ${ }^{1}$ \\ ${ }^{1}$ Physiology Unit, School of Molecular and Medical Biosciences, University of Wales Cardiff, Cardiff CF1 1SS, United \\ Kingdom, and IInstitut des Neurosciences, Centre National de la Recherche Scientifique, UMR 7624 Université Pierre et \\ Marie Curie, Paris, France
}

The action of ethosuximide (ETX) on $\mathrm{Na}^{+}, \mathrm{K}^{+}$, and $\mathrm{Ca}^{2+}$ currents and on tonic and burst-firing patterns was investigated in rat and cat thalamic neurons in vitro by using patch and sharp microelectrode recordings. In thalamocortical (TC) neurons of the rat dorsal lateral geniculate nucleus (LGN), ETX (0.75-1 mM) decreased the noninactivating $\mathrm{Na}^{+}$current, $I_{\mathrm{NaP}}$, by $60 \%$ but had no effect on the transient $\mathrm{Na}^{+}$current. In TC neurons of the rat and cat LGN, the whole-cell transient outward current was not affected by ETX (up to $1 \mathrm{~mm}$ ), but the sustained outward current was decreased by $39 \%$ at $20 \mathrm{mV}$ in the presence of ETX $(0.25-0.5 \mathrm{~mm})$ : this reduction was not observed in a low $\mathrm{Ca}^{2+}$ $(0.5 \mathrm{~mm})$ and high $\mathrm{Mg}^{2+}(8 \mathrm{~mm})$ medium or in the presence of $\mathrm{Ni}^{2+}(1 \mathrm{~mm})$ and $\mathrm{Cd}^{2+}(100 \mu \mathrm{M})$. In addition, ETX (up to $1 \mathrm{~mm}$ ) had no effect on the low-threshold $\mathrm{Ca}^{2+}$ current, $I_{\mathrm{T}}$, of TC neurons of the rat ventrobasal (VB) thalamus and LGN and in neurons of the rat nucleus reticularis thalami nor on the highthreshold $\mathrm{Ca}^{2+}$ current in TC neurons of the rat LGN.

Sharp microelectrode recordings in TC neurons of the rat and cat LGN and VB showed that ETX did not change the resting membrane potential but increased the apparent input resistance at potentials greater than $-60 \mathrm{mV}$, resulting in an increase in tonic firing. In contrast, ETX decreased the number of action potentials in the burst evoked by a low-threshold $\mathrm{Ca}^{2+}$ potential. The frequency of the remaining action potentials in a burst also was decreased, whereas the latency of the first action potential was increased. Similar effects were observed on the burst firing evoked during intrinsic $\delta$ oscillations.

These results indicate an action of ETX on $I_{\mathrm{NaP}}$ and on the $\mathrm{Ca}^{2+}$-activated $\mathrm{K}^{+}$current, which explains the decrease in burst firing and the increase in tonic firing, and, together with the lack of action on low- and high-threshold $\mathrm{Ca}^{2+}$ currents, the results cast doubts on the hypothesis that a reduction of $I_{\mathrm{T}}$ in thalamic neurons underlies the therapeutic action of this anti-absence medicine.

Key words: ethosuximide; thalamus; $\mathrm{Na}^{+}$currents; $\mathrm{K}^{+}$currents; $\mathrm{Ca}^{2+}$ currents; tonic firing; burst firing; absence epilepsy
Bilaterally synchronous, $3 \mathrm{~Hz}$ spike and wave discharges (SWDs) occurring spontaneously over the neocortex and thalamus are the characteristic feature of primary generalized, petit mal epilepsy (absence) (Avoli et al., 1990; Malafosse et al., 1994; Roger et al., 1994; Niedermeyer, 1996). The functional connectivity between thalamus and cortex is necessary for the generation of SWDs (Williams, 1953; Gloor and Fariello, 1988; Marescaux et al., 1992; Snead, 1995; Niedermeyer, 1996), and extracellular recordings in two experimental models of absence epilepsy have shown that the presence of SWDs in the EEG is associated with high-frequency $(200-500 \mathrm{~Hz})$ bursts of action potentials in thalamocortical (TC)

\footnotetext{
Received Dec. 29, 1997; revised April 10, 1998; accepted April 16, 1998.

This work was supported by the Wellcome Trust (Grant 37089), the Centre National de la Recherche Scientifique (Unité de Recherche Associée 1488), the European Union (Biomed 2, Grant 97-2093), and the British Council (Alliance). S.R.W. was a Wellcome Prize Student. We thank Professor D. Paupardin-Tritsch for comments on this manuscript, Professor C. Marescaux for providing the GAERS rats, Mr. T. M. Gould for technical assistance, and Mr. R. A. Jones for photography. Correspondence should be addressed to Dr. Vincenzo Crunelli, Physiology Unit, School of Molecular and Medical Biosciences, University of Wales Cardiff, Museum Avenue, Cardiff CF1 1SS, UK.

Dr. Asprodini's present address: Department of Pharmacology, University of Thessaly, Larisa, Greece.

Dr. Turner's present address: Department of Visual Science, Institute of Ophthalmology, London EC1V, UK.

Dr. Williams' present address: Division of Neuroscience, John Curtin School of Medical Research, Australian National University, Canberra, ACT 0200, Australia. Copyright (C) 1998 Society for Neuroscience $0270-6474 / 98 / 184842-12 \$ 05.00 / 0$
}

neurons (Avoli et al., 1990; Inoue et al., 1993). This characteristic firing pattern of TC neurons is evoked by low-threshold $\mathrm{Ca}^{2+}$ potentials (LTCPs) (Deschênes et al., 1984; Jahnsen and Llinás, 1984) that result from the activation of the T-type low-threshold $\mathrm{Ca}^{2+}$ current, $I_{\mathrm{T}}$ (Coulter et al., 1989a; Crunelli et al., 1989; Hernandez-Cruz and Pape, 1989; Suzuki and Rogawski, 1989). These data are corroborated in part by the evidence that $40 \%$ of TC neurons in the anesthetized cat show LTCP-mediated burst firing during spontaneous spike and wave complexes, whereas the remaining $60 \%$ shows an inhibition of firing characterized by rhythmic IPSPs over a background of a steady hyperpolarization (Steriade and Contreras, 1995).

Ethosuximide (ETX) is a drug effective in the treatment of absence epilepsy, but not of other generalized epilepsies (Brown et al., 1975; Malafosse et al., 1994; McNamara, 1995). It has been shown that ETX applied at therapeutically relevant concentrations (0.25-0.75 mm) (Sherwin, 1989) produces up to $40 \%$ reduction in the amplitude of $I_{\mathrm{T}}$ in $77 \%$ of acutely dissociated TC neurons of the guinea pig and rat ventrobasal (VB) thalamus (VB) (Coulter et al., 1989b,c, 1990a) with no change in its kinetics or steady-state properties. Other succinimide antiepileptics have a similar action on $I_{\mathrm{T}}$ of VB neurons (Coulter et al., 1990a), and a more recent study has shown that ETX can reduce $I_{\mathrm{T}}$ in all neurons of the VB and the nucleus reticularis thalami (NRT) maintained in slices (Huguenard and Prince, 1994). On the basis 
of these experimental data, and because of the critical role played by $I_{\mathrm{T}}$ in the high-frequency burst firing of thalamic neurons (see above), it has been proposed that the reduction of $I_{\mathrm{T}}$ in these neurons by ETX is an important mechanism by which this antiabsence drug exerts its therapeutic action (Coulter et al., 1989b,c, 1990b; Huguenard and Prince, 1994). Such a selective action, therefore, would distinguish it from other antiepileptics effective against generalized and focal seizures (Rogawski and Porter, 1990; Selzer and Dichter, 1992; Upton, 1994; McNamara, 1995; Bradley et al., 1996).

However, whereas a decrease of $I_{\mathrm{T}}$ by ETX also has been reported in rat NRT neurons (but only at $5 \mathrm{mM}$ ) (Tsakiridou et al., 1995) and in cultured rat dorsal root ganglion cells (Kostyuk et al., 1992), other studies have failed to indicate any action of ETX on the T-type $\mathrm{Ca}^{2+}$ current of rat thalamic neurons in culture (Pfrieger et al., 1992), of human neocortical neurons in slices (Sayer et al., 1993), of three types of rat hippocampal neurons in slices (Thompson and Wong, 1991), and of GH3 pituitary cells in culture (Herrington and Lingle, 1992). A heterogeneity of T-type $\mathrm{Ca}^{2+}$ channels in different types of neurons might account for the different results between the studies of Coulter et al. (1989a-c, 1990a,b) and all of the investigations mentioned above, but it cannot explain the lack of action of ETX in thalamic neurons reported by Pfrieger et al. (1992).

In view of the discrepancies on the action of ETX on T-type $\mathrm{Ca}^{2+}$ currents, the lack of detailed studies on the ETX action on other voltage-activated currents in thalamic or cortical neurons, and the absence of LTCP-mediated burst firing in $60 \%$ of cat TC neurons during spontaneous spike and wave complexes, we have investigated the effects of this anti-absence drug on action potential firing patterns and $\mathrm{Na}^{+}, \mathrm{K}^{+}$, and $\mathrm{Ca}^{2+}$ currents in rat and cat thalamic neurons (maintained in slices or freshly dissociated) by using sharp and patch electrode recordings.

Preliminary reports of some of these results have been published (Crunelli et al., 1995; Erdemli and Crunelli, 1997).

\section{MATERIALS AND METHODS}

Preparation of slices and dissociated neurons. For patch electrode recordings, VB and dorsal lateral geniculate nucleus (LGN) slices were prepared from Wistar or Sprague Dawley rats (10-18 d old) as described previously (Guyon and Leresche, 1995; Le Feuvre et al., 1997; Parri and Crunelli, 1998). Briefly, for VB slices $(250 \mu \mathrm{m}$ thick) the brain was removed quickly and placed in an ice-cold $\left(1-4^{\circ} \mathrm{C}\right)$ medium containing (in mM): $\mathrm{KCl} 5, \mathrm{KH}_{2} \mathrm{PO}_{4} 1.25, \mathrm{CaCl}_{2} 1, \mathrm{MgSO}_{4} 5, \mathrm{NaHCO}_{3} 16$, glucose 10 , and sucrose 250 . Then a block of brain tissue containing the thalamus was glued, ventral surface uppermost, to the stage of a vibroslice (Campden Instruments, UK), and horizontal sections containing the ventral posterolateral, the ventral posteromedial, and the NRT were prepared by using the internal capsule and the medial lemniscus as landmarks. For LGN slices (250-350 $\mu \mathrm{m}$ thick) a block of tissue containing the relevant part of the thalamus was placed in an ice-cold $\left(1-4^{\circ} \mathrm{C}\right)$ medium containing (in mM): $\mathrm{NaCl} 125, \mathrm{KCl} 5, \mathrm{KH}_{2} \mathrm{PO}_{4} 1.25, \mathrm{CaCl}_{2} 1, \mathrm{MgSO}_{4} 5$, $\mathrm{NaHCO}_{3} 16$, and glucose 10 and sectioned in a plane parallel to the optic tract. After sectioning, both VB and LGN slices were maintained at room temperature in a storage chamber containing a continuously oxygenated $\left(95 \% \mathrm{O}_{2} / 5 \% \mathrm{CO}_{2}\right.$ ) medium composed of (in $\mathrm{mM}$ ): $\mathrm{NaCl} 125, \mathrm{KCl} 2-5$, $\mathrm{KH}_{2} \mathrm{PO}_{4} 1.25, \mathrm{CaCl}_{2} 1-2, \mathrm{MgSO}_{4} 1-5, \mathrm{NaHCO}_{3} 16$, and glucose 10 .

For the enzymatic dissociation of TC neurons, LGN slices prepared as described above were incubated in a medium containing (in $\mathrm{mM}$ ): $\mathrm{NaCl}$ 125, $\mathrm{KCl} 2.5, \mathrm{NaH}_{2} \mathrm{PO}_{4} 1.25, \mathrm{CaCl}_{2} 0.4, \mathrm{MgCl}_{2} 1, \mathrm{NaHCO}_{3} 26$, and glucose 25 plus trypsin (Sigma type XI, $1 \mathrm{mg} / \mathrm{ml}$ ), pH 7.3. To stop enzymatic activity, we transferred slices to a trypsin-free medium with $20 \%$ fetal bovine serum albumin. The only experiments conducted in dissociated neurons are those shown in Figure $3 D$.

For sharp microelectrode recordings, rat (Wistar, $250 \mathrm{gm}$ ) and cat (1-3.5 kg) LGN slices and rat VB slices were prepared as described previously (Williams et al., 1996, 1997a; Turner et al., 1997). Slices (400 $\mu \mathrm{m}$ thick) were kept in a continuously oxygenated $\left(\mathrm{O}_{2} 95 \% / \mathrm{CO}_{2} 5 \%\right)$ storage bath at room temperature and then transferred, when required, to an interface-type recording chamber.

Isolation and analysis of $\mathrm{Na}^{+}$currents. The internal pipette solution contained (in mM): CsF 120, HEPES 10, EGTA 10, $\mathrm{MgCl}_{2} 2, \mathrm{CaCl}_{2} 1$, $\mathrm{Na}_{2}$-ATP 4, and GTP 0.5, pH 7.3, 290 mOsm. The extracellular solution contained (in $\mathrm{mM}$ ): $\mathrm{NaCl} 120, \mathrm{Na}-\mathrm{HEPES} \mathrm{16,} \mathrm{KCl} 2$, glucose 10, tetraethylamonium-Cl (TEA-Cl) $20, \mathrm{CaCl}_{2}$ 1, 4-aminopyridine $2, \mathrm{MgCl}_{2}$ 4, $\mathrm{NiCl}_{2}$ 0.5, and $\mathrm{CdCl}_{2}$ 0.1, $\mathrm{pH} 7.4,300 \mathrm{mOsm}$. Experiments were conducted at room temperature with an Axopatch 200A (Axon Instruments, Foster City, CA). Patch electrodes had resistances of 1-4 M $\Omega$ when they were filled with $\mathrm{CsF}$ internal solution and were coated with SYLGARD (Corning, Corning, NY) to counteract capacitance artifacts. Series resistances $(4-10 \mathrm{M} \Omega$ ) were compensated $(60-80 \%)$ by using the compensatory circuits of the amplifier. Currents were sampled at $40 \mathrm{kHz}$, filtered with a low-pass Bessel filter at $5 \mathrm{kHz}$, and were corrected on-line for junctional potential, linear leakage, and capacitative current as described in Parri and Crunelli (1998). Voltage protocols consisted of voltage ramps of $0.2 \mathrm{mV} / \mathrm{msec}$ from -100 to $50 \mathrm{mV}$ or voltage steps from -110 to $10 \mathrm{mV}$, delivered alternatively every $20 \mathrm{sec}$.

Isolation and analysis of $\mathrm{K}^{+}$currents. These experiments were performed by using "blind" patch electrode recordings in slices that were maintained at room temperature in a continuously aerated $\left(95 \% \mathrm{O}_{2} / 5 \%\right.$ $\mathrm{CO}_{2}$ ) medium containing (in $\mathrm{mM}$ ): $\mathrm{NaCl} 134, \mathrm{KCl} 2, \mathrm{KH}_{2} \mathrm{PO}_{4} 1.25$, $\mathrm{Mg}_{2} \mathrm{SO}_{4} 1, \mathrm{CaCl}_{2} 2, \mathrm{NaHCO}_{3} 16$, glucose 10, and TTX 0.001, pH 7.3. Patch electrodes were filled with (in mM) $\mathrm{KMeSO}_{4} 118$, KCl 18, HEPES 10, EGTA 1, $\mathrm{CaCl}_{2}$ 0.1, adenosine 5'-triphosphate (Mg-ATP) 2, guanosine 5'-diphosphate (Na-GTP) 0.3, and $\mathrm{NaCl} 8, \mathrm{pH} 7.3,310 \mathrm{mOsm}$. Data from whole-cell recordings in which the electrode series resistance increased above $14 \mathrm{M} \Omega$ were discarded. The criteria used to identify TC neurons included the presence of a relatively large inward rectification, LTCPs, and strong outward rectification (Williams et al., 1996).

Currents were amplified by an Axopatch 1D (Axon Instruments), corrected for junctional potential, sampled at $40 \mathrm{kHz}$, filtered with a low-pass Bessel filter at $5 \mathrm{kHz}$, and analyzed with the pCLAMP. Neurons were clamped around the resting membrane potential $(-70 \mathrm{mV})$, and voltage-dependent currents were elicited by $1 \mathrm{sec}$ hyperpolarizing and depolarizing voltage steps.

Isolation and analysis of $\mathrm{Ca}^{2+}$ currents. VB and LGN slices were perfused with a medium containing (in $\mathrm{mM}$ ): $\mathrm{NaCl} 125, \mathrm{KCl} 5, \mathrm{KH}_{2} \mathrm{PO}_{4}$ $1.25, \mathrm{CaCl}_{2} 2, \mathrm{MgSO}_{4} 1, \mathrm{NaHCO}_{3} 16$, and glucose 10 , whereas isolated cells were perfused with a solution containing (in mM): $\mathrm{NaCl} 160, \mathrm{KCl}$ 2.8, $\mathrm{CaCl}_{2} 1$, and Na-HEPES 10. $\mathrm{CsCl}(2 \mathrm{~mm})$, TEA (10 mM), 4-aminopyridine (4-AP; $1 \mathrm{mM})$, and TTX $(0.0005 \mathrm{~mm})$ were present in all experiments on slices and dissociated neurons. Patch pipettes contained (in mM): $\mathrm{CsCl} 115, \mathrm{CaCl}_{2} 1, \mathrm{MgCl}_{2}$ 5, K-EGTA 10, K-HEPES 10, Na-ATP 4, Na-GTP 0.4 , and phosphocreatine 15 plus $50 \mathrm{U} / \mathrm{ml}$ of creatine phosphokinase, $\mathrm{pH} 7.3,305 \mathrm{mOsm}$. In a few experiments $\mathrm{CsF}$ was used instead of $\mathrm{CsCl}$, and, because the results obtained with the two internal solutions were similar, data were pooled. All of the experiments were conducted at room temperature, and patch electrodes were connected to an Axopatch 200A or 1D. Series resistances (4-10 M $\Omega$ ) were compensated $(60-80 \%)$ by using the compensatory circuits of the amplifier. Currents were sampled at $40 \mathrm{kHz}$, filtered with a low-pass Bessel filter at $5 \mathrm{kHz}$, and corrected on-line for linear leakage and capacitative current, as described in Guyon and Leresche (1995).

For the activation curve of $I_{\mathrm{T}}$, after a 2-sec-long prepulse to $-110 \mathrm{mV}$, voltage commands increasing by $2.5 \mathrm{mV}$ steps (up to $-47.5 \mathrm{mV}$ ) were applied. For the inactivation curves, 2-sec-long prepulses of graded (2.5 $\mathrm{mV}$ ) increasing (from -110 to $-70 \mathrm{mV}$ ) amplitude were injected before a voltage command to $-50 \mathrm{mV}$. Normalized activation and inactivation curves were fit with a Boltzmann equation of the form $y=1 /\left(1+e^{\left(V_{1 / 2}\right.}\right.$ - $V) / k$ ) (cf. Guyon and Leresche, 1995), where $V_{1 / 2}$ is the half(in)activation potential and $k$ is the steepness coefficient. The $I_{\mathrm{T}}$ time constant of decay was calculated by fitting a single exponential function to averaged $(n=5)$ currents.

Sharp microelectrode recordings. Slices were perfused with a warmed $\left(35 \pm 1^{\circ} \mathrm{C}\right)$, oxygenated $\left(\mathrm{O}_{2} 95 \% / \mathrm{CO}_{2} 5 \%\right)$ medium containing (in $\mathrm{mM}$ ): $\mathrm{NaCl} 134, \mathrm{KCl} 2, \mathrm{KH}_{2} \mathrm{PO}_{4} 1.25, \mathrm{CaCl}_{2} 2, \mathrm{MgSO}_{4} 1, \mathrm{NaHCO}_{3} 16$, and glucose 10 . Electrodes contained $1 \mathrm{M}$ potassium acetate and were connected to an Axoclamp 2A (Axon Instruments) configured in currentclamp mode. Voltage and current records were stored on a Biological DAT recorder (Intracel, Royston, UK) for later analysis with pCLAMP. Analysis of the frequency of $\delta$ oscillations was performed by constructing cumulative integrative frequency plots (Pirchio et al., 1997; Williams et 
$A_{1}$

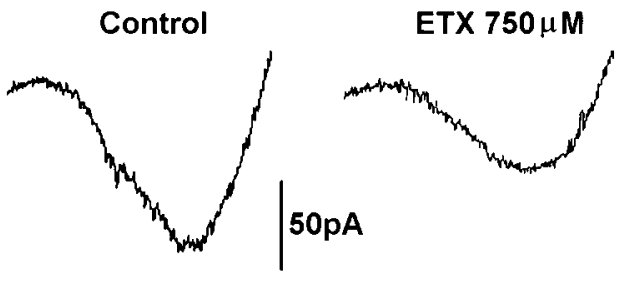

B

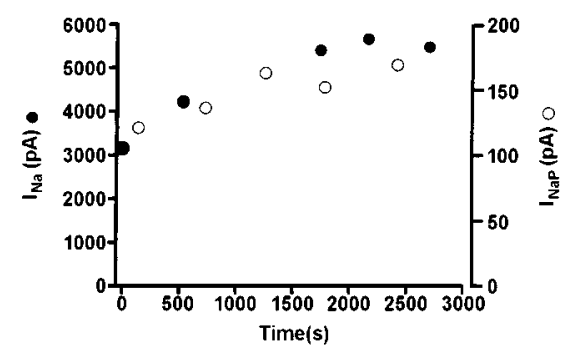

D

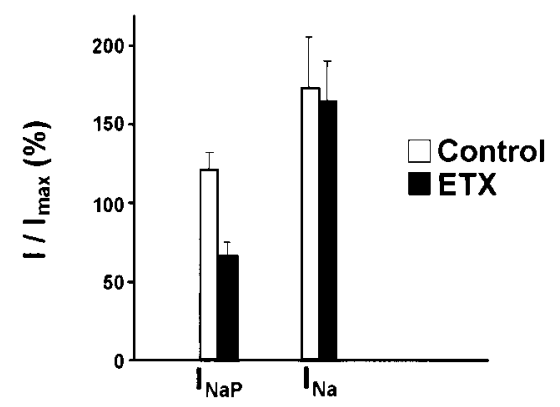

$\mathbf{A}_{2}$

Wash

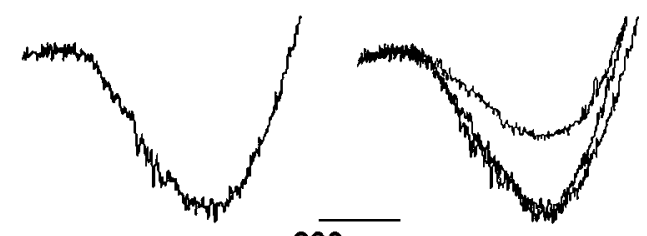

$200 \mathrm{msec}$

C

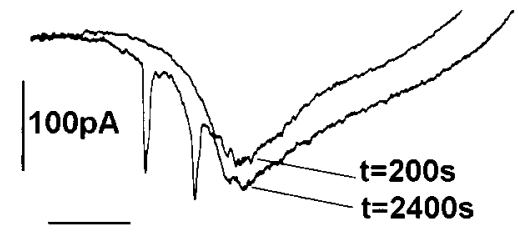

$150 \mathrm{msec}$

$\mathbf{E}$

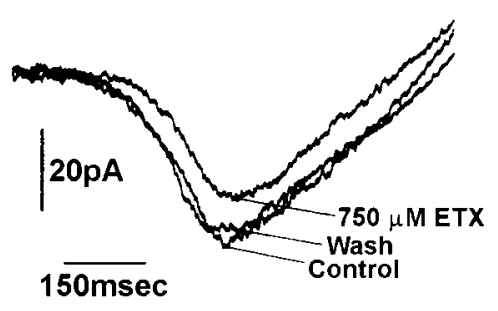

Figure 1. ETX reduces the amplitude of $I_{\mathrm{NaP}}$ in TC neurons. $A_{1}$, Whole-cell currents elicited by a voltage ramp protocol (see Materials and Methods) in a rat TC LGN neuron show the reversible reduction of $I_{\mathrm{NaP}}$ by ETX $(750 \mu \mathrm{M})$ applied by using a relatively fast perfusion system. $A_{2}$, Superimposition of the three traces shown in $A_{1}$. B, Time course of the wash-in of $I_{\mathrm{Na}}$ (filled circles) and $I_{\mathrm{NaP}}$ (open circles) recorded in the same rat LGN neuron. Time 0 indicates the time of break-in. $C$, Whole-cell currents elicited by a voltage ramp protocol in a rat LGN TC neuron show the increase in $I_{\mathrm{NaP}}$ observed 40 min after break-in. $D$, The bar graph illustrates the action of ETX (applied with a slow perfusion system) on $I_{\mathrm{NaP}}$ and $I_{\mathrm{Na}}$. The histograms show the amplitude of $I_{\mathrm{NaP}}$ and $I_{\mathrm{Na}}$ measured 40 min after break-in and normalized with respect to the corresponding maximal current recorded 1-3 min after break-in. The open bars (Control) show the increase in the size of the two currents, measured 40 min after break-in in neurons that were not treated with ETX, whereas the filled bars represent the amplitude of the currents in neurons perfused with $750 \mu \mathrm{M}$ ETX. Note that the same two groups of ETX-treated and untreated neurons were used to produce the $I_{\mathrm{NaP}}$ and $I_{\mathrm{Na}}$ graphs. $E$, Whole-cell currents illustrate the reversibility of the effect of ETX $(750 \mu \mathrm{M})$ on $I_{\mathrm{NaP}}$ in another rat LGN TC neuron. These records were obtained 3 min (Control), $40 \mathrm{~min}($ ETX), and 55 min (Wash) after break-in. ETX had been applied for $30 \mathrm{~min}$ at the time the ETX-marked trace was recorded.

al., 1997a) in which the $50 \%$ frequency probability represents the mean interevent interval.

Drugs and statistics. ETX was purchased from Sigma (UK and France) and kindly provided by Parke-Davis (UK); 6-cyano-7-nitroquinoxaline2,3-dione (CNQX) and DL-2-amino-5-phosphonovaleric acid (AP5) were purchased from Tocris Neuramin (Bristol, UK); 1-(4-amino-phenyl)-4methyl-7,8-methylene-dioxy- ${ }^{5} \mathrm{H}-2,3$-benzodiazepine (GYKI 52466) was a gift from Dr. Istvan Tarnawa (Institute for Drug Research, Budapest, Hungary); ( \pm )-5-methyl-10,11-dihydro- ${ }^{5} \mathrm{H}$-dibenzo[a,d]cyclo-hepten5,10-imine hydrogen maleate (MK-801) was kindly provided by Merck, Sharp \& Dohme (UK); and EGTA, TTX, TEA, and 4-AP were obtained from Sigma (France and UK).

All quantitative data are expressed in the text and figures as mean \pm SEM, and statistical significance was tested with Student's $t$ test.

\section{RESULTS}

\section{Action of ETX on $\mathrm{Na}^{+}$currents in TC neurons}

The noninactivating $\mathrm{Na}^{+}$current, $I_{\mathrm{NaP}}$, was elicited in LGN TC neurons by voltage ramp, using a voltage ramp protocol similar to that previously described by Parri and Crunelli (1998) (see Materials and Methods). Using a relatively fast perfusion system (which allowed us to obtain a full block of $I_{\mathrm{NaP}}$ and $I_{\mathrm{Na}}$ by $1 \mu \mathrm{M}$ TTX in $\sim 60 \mathrm{sec})$, we found that ETX $(0.75-1 \mathrm{~mm})$ produced a maximal reduction of $I_{\mathrm{NaP}}(60 \pm 7 \% ; n=6)$ after $90-120 \mathrm{sec}$ from switching to the ETX-containing medium (Fig. $1 A_{1}, A_{2}$ ). This effect appeared to be fully reversible in two TC neurons (Fig. $1 A_{1}, A_{2}$ ), although in the remaining four neurons the amplitude of $I_{\mathrm{NaP}}$ after wash-out of the drug appeared larger than in control conditions (data not shown). A possible reason for this finding might have been that $I_{\mathrm{NaP}}$, as well as the transient $\mathrm{Na}^{+}$ current $\left(I_{\mathrm{Na}}\right)$, showed a slow but consistent increase in amplitude with time, which was already evident 5-8 min after break-in and appeared to reach a plateau at $\sim 40 \mathrm{~min}$ after break-in (Fig. $1 B, C)$. Thus, $I_{\mathrm{NaP}}$ and $I_{\mathrm{Na}}$ had increased by $22 \pm 8 \%(n=6)$ and $74 \pm 34 \%(n=3)$, respectively, compared with their amplitude 
1-3 min after break-in (open bars in Fig. $1 D)\left(I_{\mathrm{NaP}}\right.$, from $102 \pm$ 5 to $126 \pm 8 \mathrm{pA} ; I_{\mathrm{Na}}$, from $2.1 \pm 0.2$ to $3.5 \pm 1.1 \mathrm{nA}$ ). In six other TC neurons, $I_{\mathrm{NaP}}$ and $I_{\mathrm{Na}}$ were measured 1-3 min after break-in and then at $40 \mathrm{~min}$ after break-in following a 30 min continuous perfusion with $0.75 \mathrm{~mm}$ ETX. $I_{\mathrm{NaP}}$ measured in the ETX-treated neurons was smaller than (1) $I_{\mathrm{NaP}}$ seen 1-3 min after break-in $(38 \pm 12 \% ; p<0.05)$, and (2) $I_{\mathrm{NaP}}$ observed in the ETXuntreated neurons 40 min after break-in $(57 \pm 9 \%$; $p<0.005)$ (open and filled bars in Fig. $1 D$ ). In contrast, the amplitude of $I_{\mathrm{Na}}$ was similar between ETX-treated and untreated neurons (open and filled bars in Fig. $1 D$, respectively). The reversibility of the effect of ETX after these long applications can be seen in Figure $1 E$.

\section{Action of ETX on $\mathrm{K}^{+}$currents in TC neurons}

ETX (0.25-0.5 mM) had no substantial effect on the whole-cell transient outward current but reversibly decreased the sustained outward current evoked in TC neurons of the rat and cat LGN ( $n=12$ and 3 , respectively) measured by using "blind" patch electrodes containing $\mathrm{KMeSO}_{4}$ (Fig. $2 A, B$ ). The decrease in the sustained current was $39.1 \pm 6.4 \%(n=15)$ when measured at 20 $\mathrm{mV}$, and, in particular, the absolute reduction measured at -50 , -40 , and $-30 \mathrm{mV}$ was $26.1 \pm 7.5,44 \pm 2.1$, and $62.7 \pm 11.5 \mathrm{pA}$, respectively $(n=15)$. Recordings with KCl-containing electrodes showed a similar reduction by ETX of the sustained outward current $(31.3 \pm 6.9 \%$, measured at $20 \mathrm{mV} ; n=4)$ (data not shown). No decrease in the sustained outward current, however, was elicited by ETX in nine and three neurons from different sets of slices perfused with a low $\mathrm{Ca}^{2+}(0.5 \mathrm{~mm})$ and high $\mathrm{Mg}^{2+}(8$ $\mathrm{mm}$ ) solution (Fig. $2 C$ ) and with $\mathrm{Ni}^{2+}(1 \mathrm{~mm})$ and $\mathrm{Cd}^{2+}(100 \mu \mathrm{M})$, respectively (data not shown). These results, together with the lack of action of ETX on the leak current and high-threshold $\mathrm{Ca}^{2+}$ currents (see below) (cf. Coulter et al., 1989a-c), indicated that this drug was affecting $I_{\mathrm{K}(\mathrm{Ca})}$ and not other sustained $\mathrm{K}^{+}$currents that are present in TC neurons (Huguenard and Prince, 1991; Huguenard et al., 1991; McCormick, 1991; Budde et al., 1992).

In another series of experiments that used standard patch electrode recordings, application of ETX $(1 \mathrm{~mm})$ did not change the amplitude of transient $\mathrm{K}^{+}$current(s) in TC neurons of the rat LGN $(n=5)$ (data not shown).

\section{Action of ETX on the low-threshold $\mathrm{Ca}^{2+}$ current, $I_{\mathrm{T}}$}

The steady-state activation curve of $I_{\mathrm{T}}$ recorded from TC neurons in rat VB slices had a $V_{2}$ of $-64.9 \pm 0.1 \mathrm{mV}$ and a $k$ of $2.7 \pm 0.1$ $(n=6)$ (Fig. 3A,B). The inactivation curve indicated that $I_{\mathrm{T}}$ was inactivated in large part at membrane potentials positive to -70 $\mathrm{mV}$ and that the activation was removed gradually as the potential approached $-100 \mathrm{mV}\left(V_{1 / 2}=-84.5 \pm 0.2 \mathrm{mV} ; k=4.0 \pm 0.1\right)$ $(n=6)$. These activation and inactivation parameters were similar to those reported in dissociated TC neurons from the rat VB (Coulter et al., 1989a; Huguenard and Prince, 1992) and to those obtained for rat TC neurons in the LGN slice (Crunelli et al., 1989; Hernandez-Cruz and Pape, 1989; Guyon et al., 1993) (see also below), indicating that the steady-state properties of $I_{\mathrm{T}}$ do not differ between TC neurons in these sensory thalamic nuclei. Application of ETX $(0.3-0.75 \mathrm{~mm})$ to TC neurons in the VB slice had no effect on the amplitude and the steady-state activation and inactivation properties of $I_{\mathrm{T}}$ (activation: $V_{1 / 2}=-64.9 \pm 0.2 \mathrm{mV}$, $k=2.4 \pm 0.2$; inactivation: $V_{1 / 2}=-84.4 \pm 0.2 \mathrm{mV}, k=3.9 \pm 0.2$; $n=6$ ) (Fig. $3 A, B$ ). Indeed, the latency to peak and the time constant of decay of $I_{\mathrm{T}}$ in the absence and in the presence of ETX were similar (control, $11.9 \pm 0.7$ and $21.0 \pm 1.3 \mathrm{msec}$, respectively; ETX, $12.2 \pm 0.4$ and $21.3 \pm 1.1 \mathrm{msec}$, respectively).

The voltage dependence and the kinetic properties of $I_{\mathrm{T}}$ recorded from TC neurons $(n=9)$ in LGN slices were identical to those previously reported (Guyon et al., 1993; Guyon and Leresche, 1995), and no effect of ETX (0.5-1 mM) could be detected on the amplitude (Fig. $3 C$ ) and the voltage dependence of this current. Indeed, the latency to peak $(10.5 \pm 1.1 \mathrm{msec})$ and the time constant of decay $(17.1 \pm 0.7 \mathrm{msec})$ did not change in the presence of $\operatorname{ETX}(9.7 \pm 1.2$ and $16.8 \pm 0.8 \mathrm{msec}$, respectively).

We also recorded $I_{\mathrm{T}}$ from TC neurons $(n=23)$ dissociated from the LGN, using rats of the same age and strain (as well as experimental conditions) similar to those used by Coulter et al. $(1989 \mathrm{a}-\mathrm{c})$. All of the properties of $I_{\mathrm{T}}$ recorded in dissociated TC neurons were similar to those observed in TC neurons from LGN slices, except that the maximal amplitude of the current in dissociated cells was smaller (neurons in slices: $1.7 \pm 0.5 \mathrm{nA}, n=24$; dissociated neurons: $0.10 \pm 0.04 \mathrm{nA}, n=23$ ) (Fig. $3 D$ ). Again, no effect of ETX (0.5-1 mM) was seen on the amplitude of $I_{\mathrm{T}}$ recorded from dissociated TC neurons of the rat LGN $(n=21)$ (Fig. 3D) nor on its latency to peak and time constant of decay (control, $9.0 \pm 0.6$ and $20.6 \pm 0.9 \mathrm{msec}$, respectively; ETX, $8.8 \pm$ 0.6 and $21.3 \pm 1.1 \mathrm{msec}$, respectively). At the end of some of these experiments the application of $\mathrm{Ni}^{2+}(0.4 \mathrm{~mm})$ markedly reduced (75-95\%) the peak amplitude of $I_{\mathrm{T}}$ in TC neurons.

Although the biophysical properties of $I_{\mathrm{T}}$ in LGN TC neurons are identical between nonepileptic control animals and the Genetically Absent Epileptic Rats from Strasbourg (GAERS) (Guyon et al., 1993), the sensitivity of $I_{\mathrm{T}}$ to ETX might have been different between these animal groups. As shown in Figure $3 E$, however, $0.75 \mathrm{~mm}$ ETX did not affect the maximal amplitude of $I_{\mathrm{T}}$ in TC neurons $(n=6)$ from LGN slices of GAERS rats, nor did it change the latency to peak or time constant of decay (control, $12.3 \pm 1.0$ and $22.8 \pm 2.7 \mathrm{msec}$, respectively; ETX, $11.2 \pm 1.1$ and $22.4 \pm 3.5 \mathrm{msec}$, respectively).

The NRT has been suggested to play a role in SWDs (Avanzini et al., 1993), and the $I_{\mathrm{T}}$ recorded from NRT neurons has been shown to be decreased by ETX and by the succinimide antiepileptic $\alpha$-methyl- $\alpha$-phenyl-suximide (Huguenard and Prince, 1994; Tsakiridou et al., 1995). However, we could not detect any action of ETX $(0.75 \mathrm{~mm})$ on the maximal amplitude of $I_{\mathrm{T}}$ recorded from NRT neurons $(n=4)$ in slices (Fig. $3 F)$.

\section{Action of ETX on high-threshold $\mathrm{Ca}^{2+}$ currents in TC neurons}

The high-threshold $\mathrm{Ca}^{2+}$ current of TC neurons shows a clear run-down with time (Fig. 3G) (cf. Guyon and Leresche, 1995). The effect of ETX, therefore, was measured relative to the extrapolated slope of the run-down, obtained by a linear regression of at least three data points recorded before drug application, as described in detail in Guyon and Leresche (1995). Applications (up to $30 \mathrm{~min}$ ) of ETX (1 mM) had no effect on the high-threshold $\mathrm{Ca}^{2+}$ current $(n=4)$, whereas in the same neurons the $\mathrm{GABA}_{\mathrm{B}}$ receptor agonist $( \pm)$-baclofen $(50 \mu \mathrm{M})$ reduced this current by $\sim 40 \%$ (Fig. $3 G$ ), as described previously (cf. Guyon and Leresche, 1995).

\section{Action of ETX on the membrane properties of TC neurons}

Sharp microelectrode recordings were used to investigate the effects of ETX on the electroresponsiveness of TC neurons in the rat and cat LGN and VB (resting membrane potential, $-64 \pm 4$ 

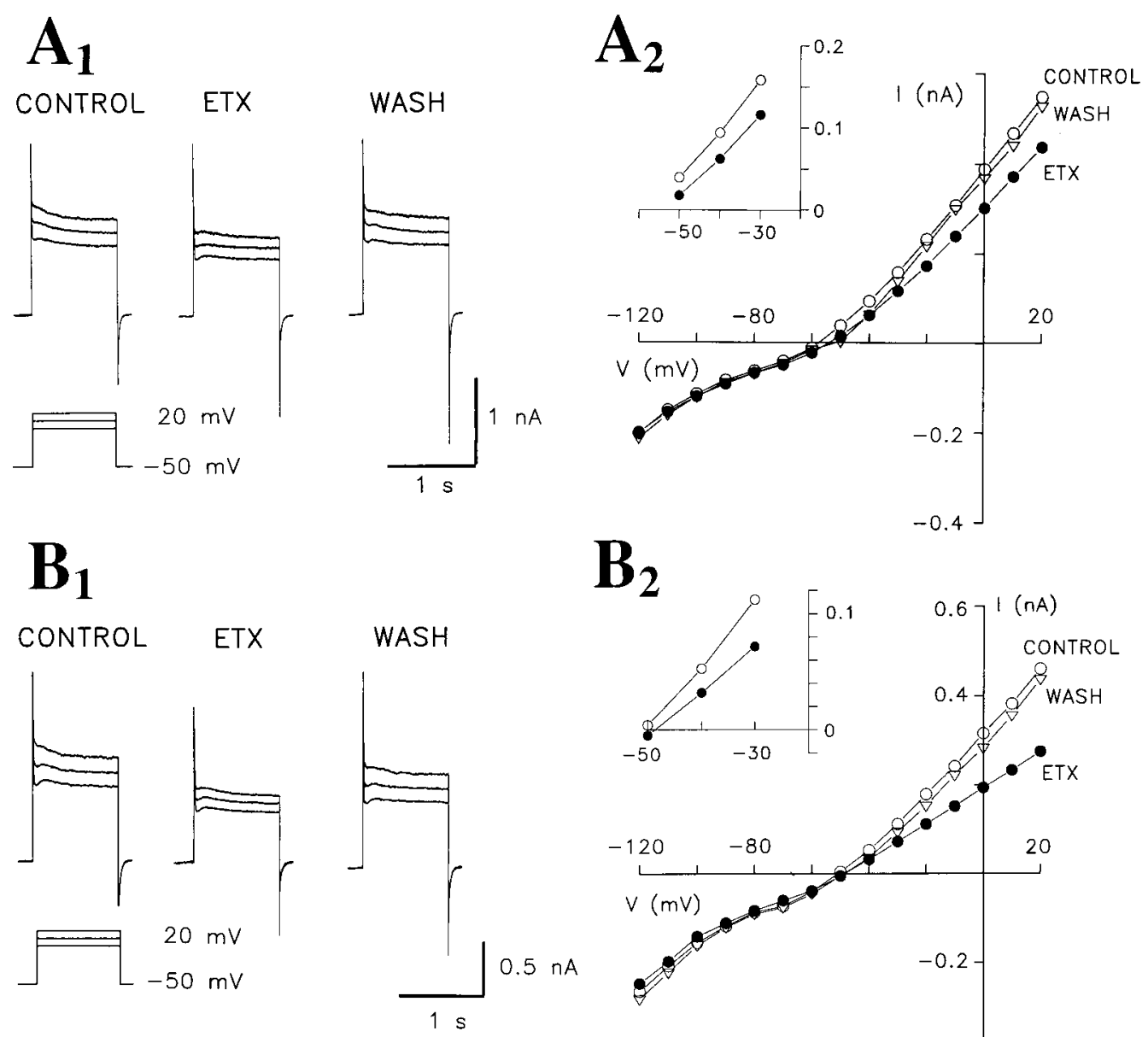

$\mathbf{B}_{2}$
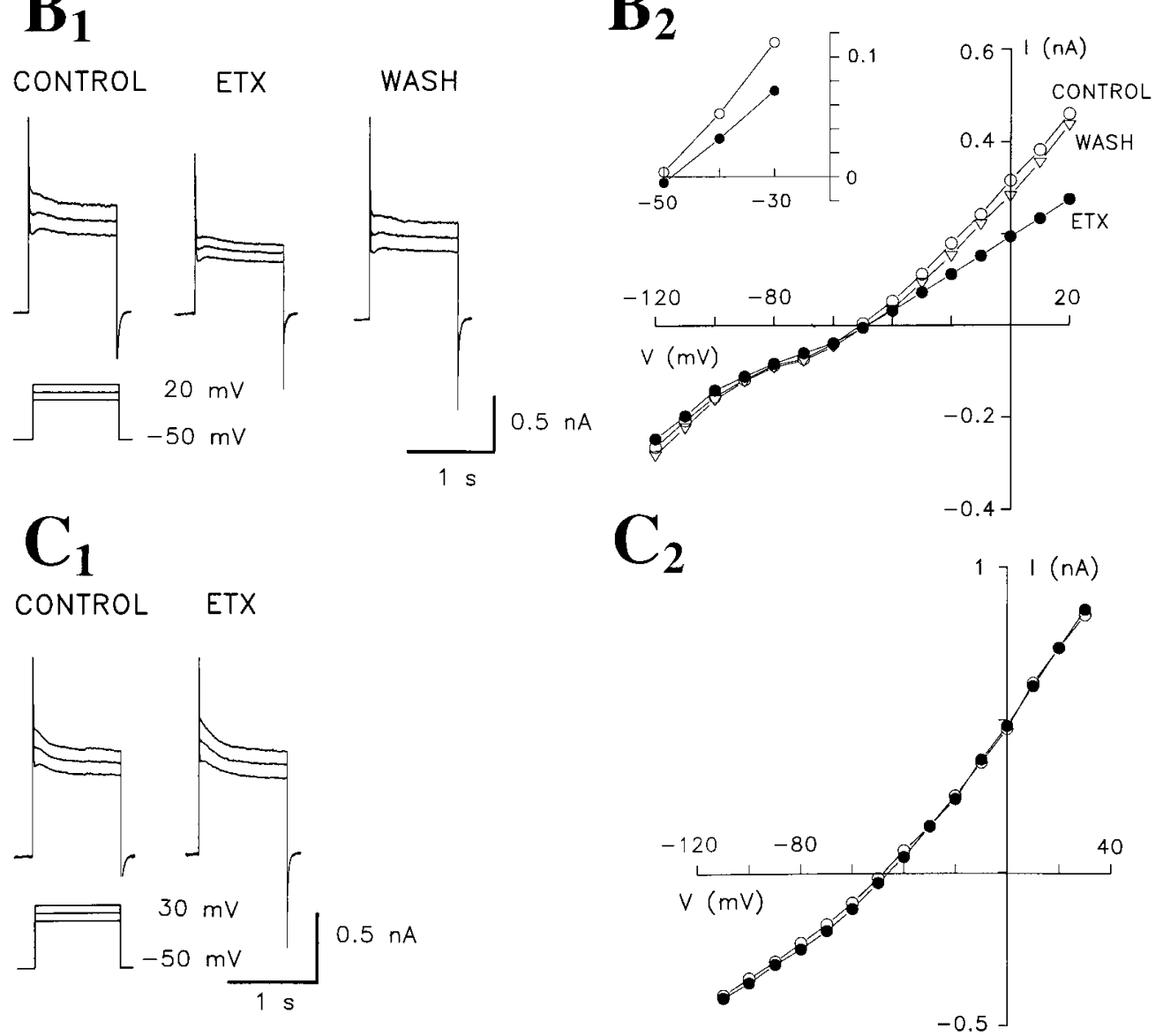

Figure 2. ETX decreases the sustained outward whole-cell current in TC neurons. $A_{1}$, Whole-cell currents show the reversible reduction by ETX ( 0.25 $\mathrm{mM}$ ) of the sustained current in a TC neuron of the rat LGN. $A_{2}$, Steady-state current-voltage plot for the same neuron as in $A_{1}$ (the inset is an enlargement of the region around the action potential threshold). $B_{1}$, Whole-cell current reduction by ETX ( $\left.0.5 \mathrm{~mm}\right)$. $B_{2}$, Steady-state current-voltage plot for the same neuron as in $B_{1}$ (the inset is an enlargement of the region around the action potential threshold). $C_{1}$, In a rat TC neuron recorded in a low $\mathrm{Ca}^{2+}(0.5 \mathrm{~mm})$ and high $\mathrm{Mg}^{2+}(8 \mathrm{mM})$ medium, ETX $(0.5 \mathrm{~mm})$ had no effect on the sustained current. $C_{2}$, Steady-state current-voltage plot for the same neuron as in $C_{1}$.

$\mathrm{mV}$; apparent input resistance, $87 \pm 13 \mathrm{M} \Omega ; n=19)$. ETX did not change the resting membrane potentials of the majority of these neurons (0.5-1.0 mM, $n=16 ; 5 \mathrm{~mm}, n=5)$ nor of TC neurons from the LGN of GAERS rats $(n=3)$, although in a few neurons a small hyperpolarization $(2-3 \mathrm{mV})$ was observed. The apparent input resistance in the hyperpolarized direction of the voltage-current relationship did not show any consistent change in the presence of ETX (Fig. $4 A_{2}, B_{2}$ ), nor was the depolarizing sag present in the voltage responses to negative current pulses affected by the addition of this drug (Fig. $4 A, B_{1}$ ), indicating that ETX had no effect on $I_{\mathrm{h}}$ (Huguenard and Prince, 1994) and other currents responsible for the inward rectification of TC neurons (Williams et al., 1997b). However, ETX did produce a small but consistent increase in the apparent input resistance at membrane 
A
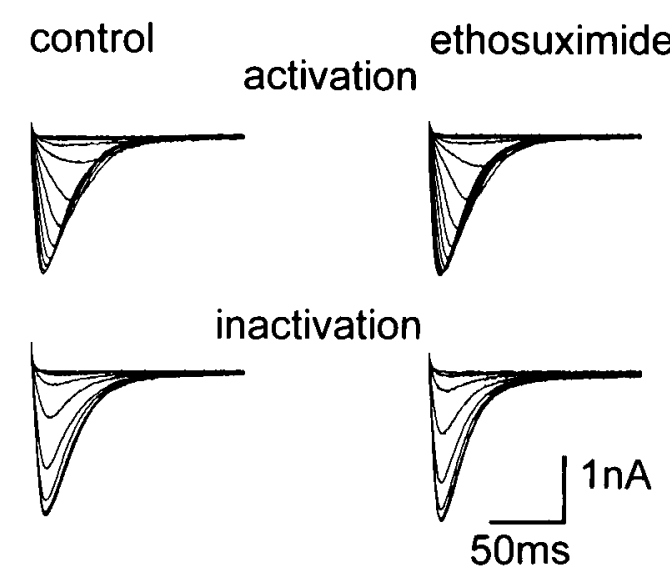
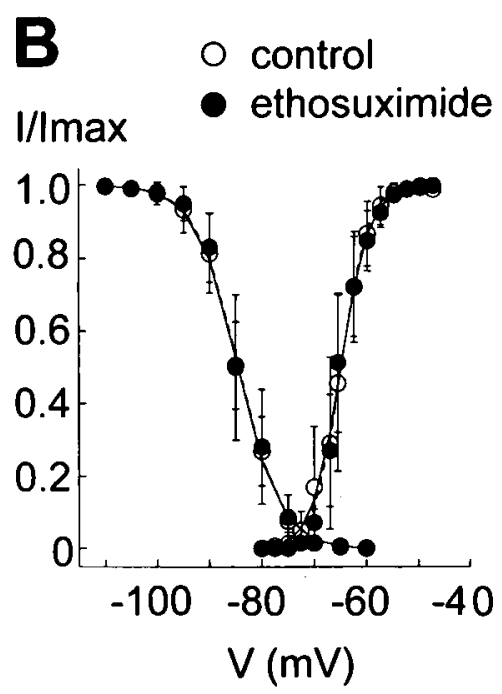

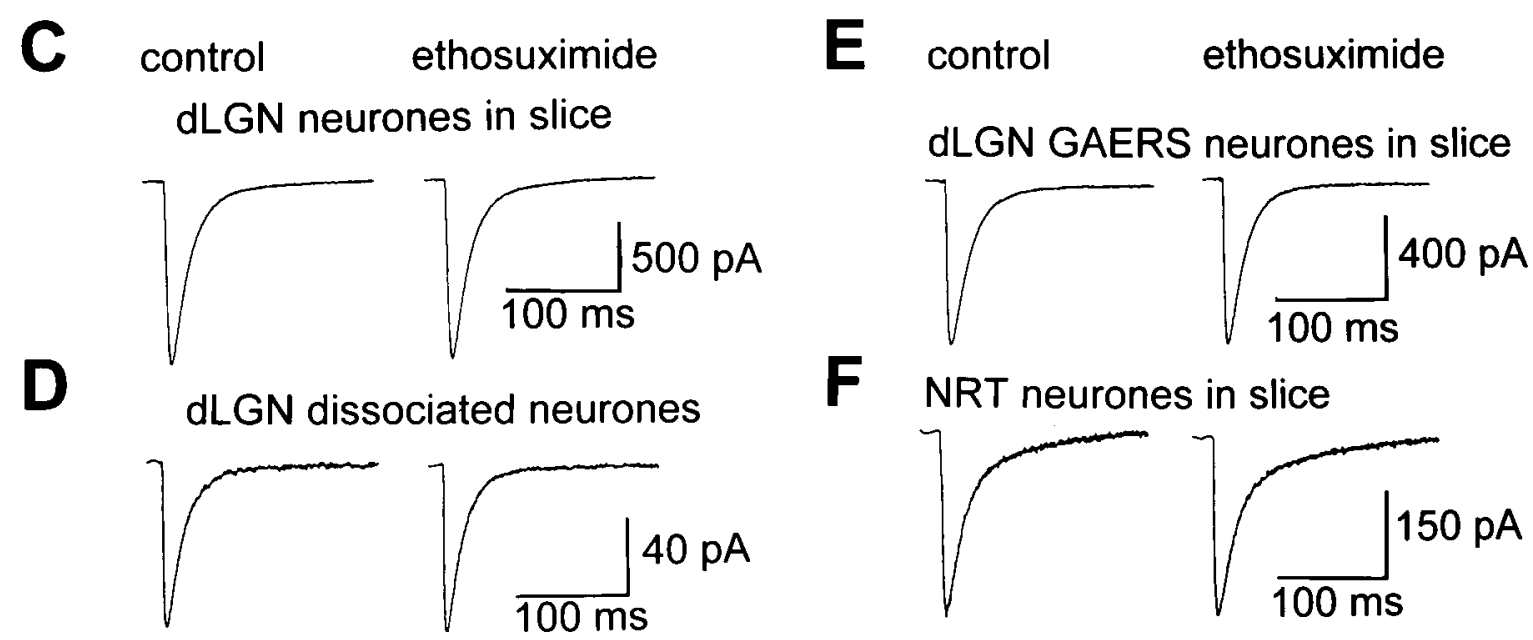

G
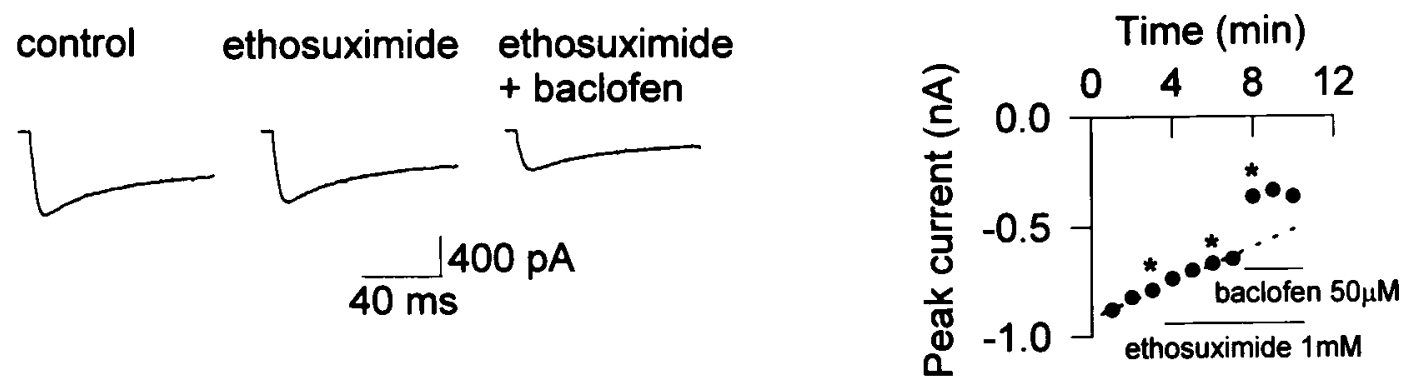

Figure 3. Lack of action of ETX on voltage-activated $\mathrm{Ca}^{2+}$ currents. $A$, Whole-cell currents show no difference between control and ETX (0.75 mM) in the amplitude and kinetics of $I_{\mathrm{T}}$ in TC neurons of VB slices (see Materials and Methods for details of voltage protocols). $B$, Normalized steady-state activation and inactivation curves show no effect of ETX $(0.75 \mathrm{~mm})$ on the voltage dependence of $I_{\mathrm{T}}$ measured in six TC neurons from rat VB slices (see Results for further details). $C-F$, Each trace (average of five records) is the maximal IT recorded in the different neurons indicated and shows the lack of action of ETX $(0.75 \mathrm{~mm}$ ) on the amplitude and kinetics of the current (for all traces the holding potential was $-110 \mathrm{mV}$, and the voltage command was $60 \mathrm{mV}$ ). Only the records in $D$ were obtained from dissociated neurons. $G$, Single traces show the lack of action of ETX (1 mM) in a TC neuron of the rat LGN on the high-threshold $\mathrm{Ca}^{2+}$ current. Subsequent application of $( \pm)$-baclofen $(50 \mu \mathrm{M})$ in the continuing presence of ETX produced a clear reduction of the peak amplitude. These data were used to construct the plot of the peak amplitude of the high-threshold $\mathrm{Ca}^{2+}$ current versus time (on the right), which clearly shows the wash-out of the current, the lack of action of ETX, and the reduction by ( \pm )-baclofen. Note how the run-down of the current is abolished in the presence of $( \pm)$-baclofen (cf. Guyon and Leresche, 1995). 
$\mathbf{A}_{1}$

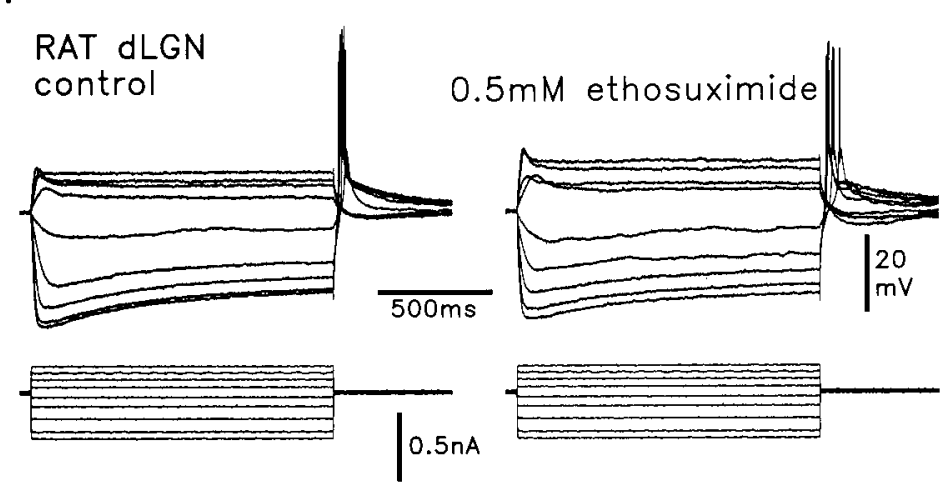

$\mathbf{B}_{1}$

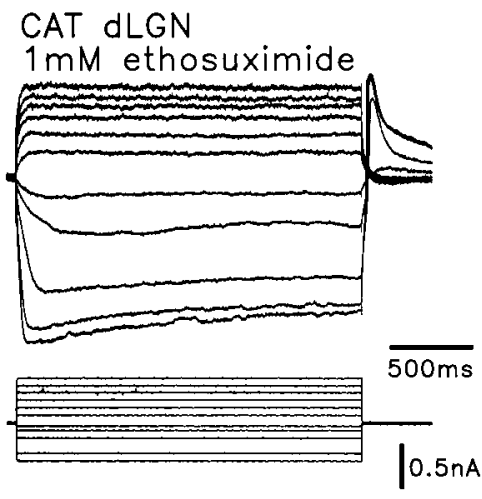

$\mathbf{A}_{2}$
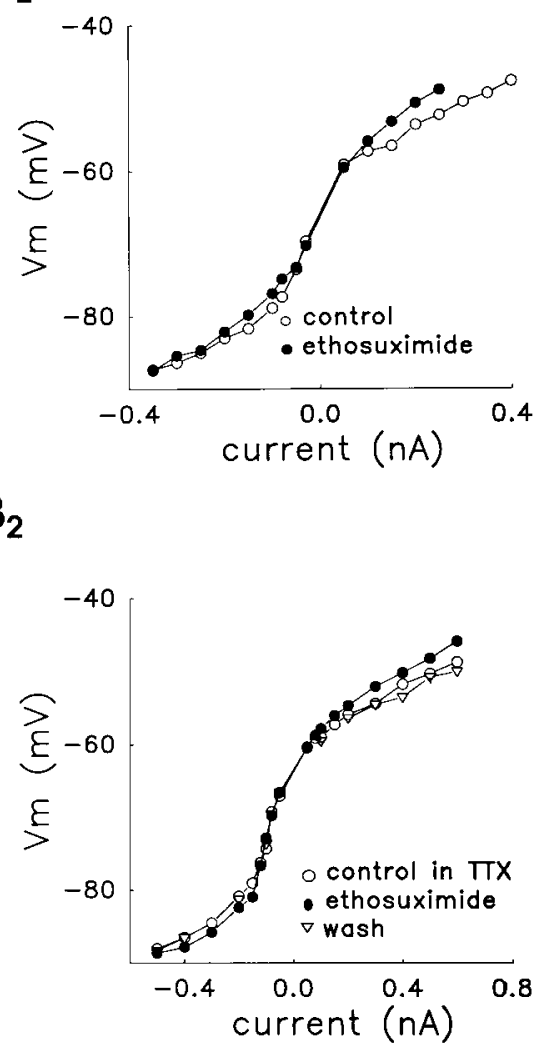

Figure 4. ETX increases the apparent input resistance of TC neurons in cat and rat LGN slices at potentials greater than $-60 \mathrm{mV} . A_{1}, B_{1}$, Families of voltage responses and input currents recorded in the absence and in the presence of ETX, using sharp electrode recordings. The records in $B_{1}$ were obtained in the presence of $1 \mu \mathrm{M}$ TTX. $A_{2}, B_{2}$, Voltage-current plots (from the same neurons as in $A_{1}$ and $B_{1}$, respectively) show an increase in the apparent input resistance at potentials greater than $-60 \mathrm{mV}$ during perfusion of the slice with ETX. Each point is the average of three measurements. The resting membrane potential is $-60 \mathrm{mV}$ in $A_{1}$ and $B_{1}$.

potentials greater than $-60 \mathrm{mV}$ (Fig. 4), an effect that was reversible after wash-out of the drug and that was insensitive to TTX (1 $\mu \mathrm{M} ; n=6)$ (Fig. $\left.4 B_{1}, B_{2}\right)$.

\section{Action of ETX on tonic firing of TC neurons}

Because of the increase in apparent input resistance, a smaller input current was required to bring the membrane potential to action potential threshold in the presence of ETX (Fig. 5A,B) (control, $0.25 \pm 0.02 \mathrm{nA}$; ETX, $0.16 \pm 0.03 \mathrm{nA} ; n=3 ; p<0.01$, measured while holding the neuron at $-60 \mathrm{mV}$ ). Thus, more action potentials were evoked in the presence than in the absence of ETX at the lowest input currents used (i.e., 0.2-0.4 nA) (Fig. $5 A)$ : indeed, the input current that in control conditions was producing the threshold voltage for action potentials would evoke $18 \pm 3(n=3)$ action potentials in the presence of ETX (Fig. 5C). In addition, the frequency of this tonic firing (measured for the third and higher interspike intervals) was increased by ETX, although this effect occurred only in a narrow range of input currents (i.e., $0.3-0.35 \mathrm{nA}$ in Fig. $5 B$ ).

\section{Action of ETX on burst firing of TC neurons}

The action of ETX on burst firing was different from its effect on tonic firing, because ETX consistently decreased (by one or two) the number of action potentials evoked by an LTCP in both rat and cat TC neurons (Fig. 6A). As for the action potentials that remained in the presence of ETX, the latency of the first action potential in the burst increased, in particular in the bursts evoked at the offset of the smallest $(5-7.5 \mathrm{mV})$ hyperpolarizing deflections (control, $29 \pm 5 \mathrm{msec}$; ETX, $53 \pm 3 \mathrm{msec}, n=3 ; p<0.01$ ) (Fig. $6 A, B)$, whereas the frequency of action potential firing within a burst showed a small but statistically significant decrease $(8 \pm 2 \% ; n=6 ; p<0.05)$ (Fig. $6 C)$. The magnitude of this effect was not increased in the presence of very high concentrations $(5$ mM) of ETX (Fig. 6C).

In $\mathrm{TC}$ neurons from cat $\mathrm{VB}$ slices we also investigated the action of ETX (0.5-1 mM) on the burst firing elicited during $\delta$ oscillations (Leresche et al., 1990, 1991; Steriade et al., 1991) recorded in the presence of DL-APV (0.1 mM), CNQX (0.02 mM), MK-801 (0.01 mM), GYKI 52466 (0.1 mm), bicuculline (0.05 mM), and CGP $35348(0.5 \mathrm{~mm})$ to block excitatory and inhibitory amino acid receptors (Fig. $7 A_{1}, A_{2}$ ). The membrane potential region of existence of $\delta$ oscillations was not affected by the presence of ETX (control, $12 \pm 3 \mathrm{mV}$; ETX, $11 \pm 2 \mathrm{mV} ; n=3$ ), indicating that ETX did not change the voltage dependence of this intrinsic activity (Leresche et al., 1991; Pirchio et al., 1997). However, ETX consistently reduced (by one or two) the number of action potentials evoked by each LTCP (Fig. $7 B_{1}$ ) and decreased the frequency of the $\delta$ oscillations so that the mean interval between the first action potential in consecutive LTCPs was increased from $513 \pm 9 \mathrm{msec}$ in control conditions to $544 \pm 3 \mathrm{msec}$ in the presence of $\operatorname{ETX~}(n=20$ data points from each of three neurons; 
A

$$
\text { control }
$$
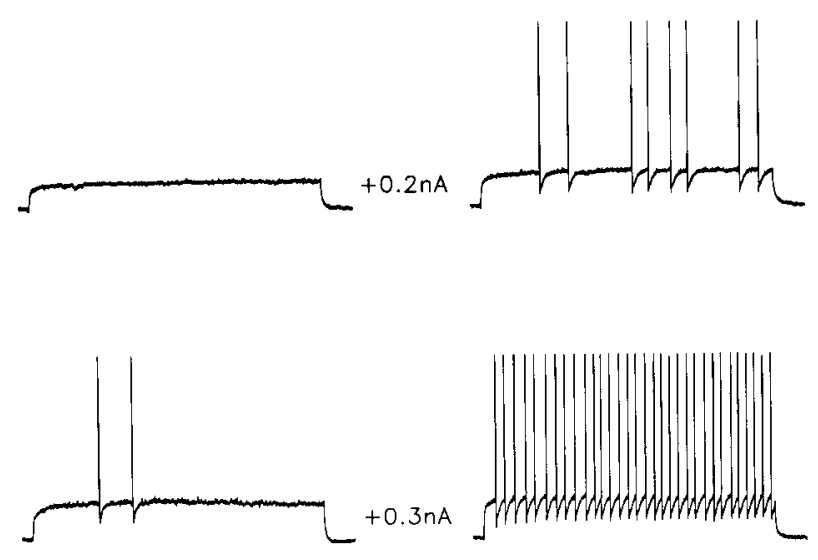

$20 \mathrm{mV}$
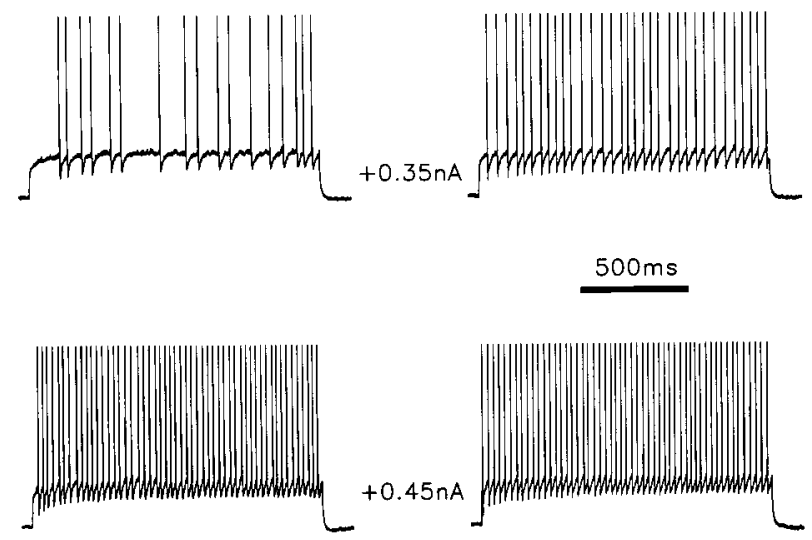

B
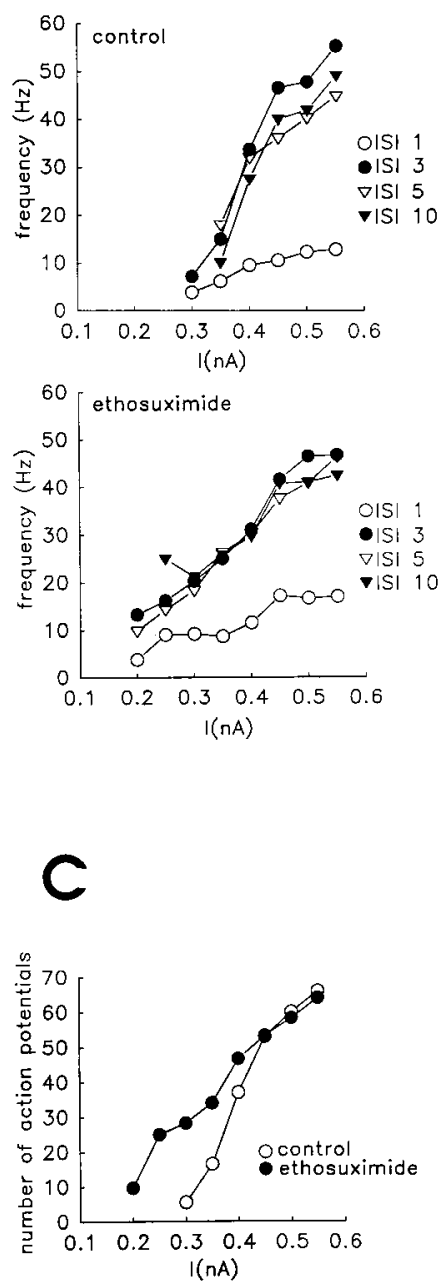

Figure 5. ETX increases tonic firing of TC neurons in slices. $A$, Depolarizing voltage pulses show an increased tonic firing in the presence of ETX (0.5 $\mathrm{mM}$ ) for similar values of injected currents (records from a cat LGN neuron). The action potential height is truncated. $B$, Plots of firing frequency versus injected current (from the data in $A$ ) show a decreased firing frequency at the third (and higher) interspike intervals (ISI) in the presence of ETX (0.5 $\mathrm{mm}$ ) for input currents of $0.3-0.35 \mathrm{nA}$. $C$, At lower input currents $(0.2-0.4 \mathrm{nA})$ the number of action potentials evoked by a pulse of 1.5 sec duration is increased in the presence of ETX $(0.5 \mathrm{mM})$ (from the data in $A$ ).

$p<0.05)$ (Fig. $\left.7 A_{2}, B_{2}\right)$. Note that this increase $(\sim 30 \mathrm{msec})$ was similar to the ETX-induced increase $(\sim 25 \mathrm{msec})$ in the latency of the first action potential of the bursts evoked at the offset of negative current steps (compare Fig. 6A,B).

\section{DISCUSSION}

The main conclusion of this investigation is that ETX has a complex action on the electroresponsiveness of rat and cat TC neurons, which includes an increase in tonic firing and a decrease in the burst firing elicited by LTCPs. These actions of ETX can be explained by the block of $I_{\mathrm{K}(\mathrm{Ca})}$ and $I_{\mathrm{NaP}}$ because ETX has no effect on low- and high-threshold $\mathrm{Ca}^{2+}$ currents nor on $I_{\mathrm{Na}}$ and other $\mathrm{K}^{+}$currents.

\section{ETX and $\mathrm{Ca}^{2+}$ currents}

The lack of action of ETX on $I_{\mathrm{T}}$ of TC and NRT neurons is in agreement with the results obtained from rat thalamic neurons in culture (Pfrieger et al., 1992), from NRT and TC neurons in mouse slices (C. Lena and J. P. Changeux, personal communication), and from other neuronal types (Thompson and Wong, 1991; Herrington and Lingle, 1992; Sayer et al., 1993). As far as the ETX-induced decrease of the low-threshold $\mathrm{Ca}^{2+}$ current recorded from dorsal root ganglion neurons is concerned (Kostyuk et al., 1992), it is worth noting that the threshold for activation of this current is $-40 \mathrm{mV}$, but it is $-70 \mathrm{mV}$ in $\mathrm{TC}$ neurons. Thus, because the biophysical properties of the lowthreshold $\mathrm{Ca}^{2+}$ channels present in dorsal root ganglion cells are different from those in the brain in general, and in the thalamus in particular, it is reasonable to suspect a different pharmacological profile to blocking agents. As far as the action of ETX on $I_{\mathrm{T}}$ in dissociated rat NRT neurons is concerned (Tsakiridou et al., 1995), it should be pointed out that this effect of ETX was observed only at a saturating concentration of $5 \mathrm{~mm}$ (i.e., approximately seven times the maximal therapeutic plasma level) and that the magnitude of $I_{\mathrm{T}}$ reduction (19\%) was only one-half of that reported for guinea pig and rat $\mathrm{VB}$ and NRT neurons of a 


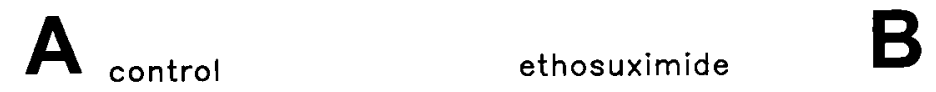

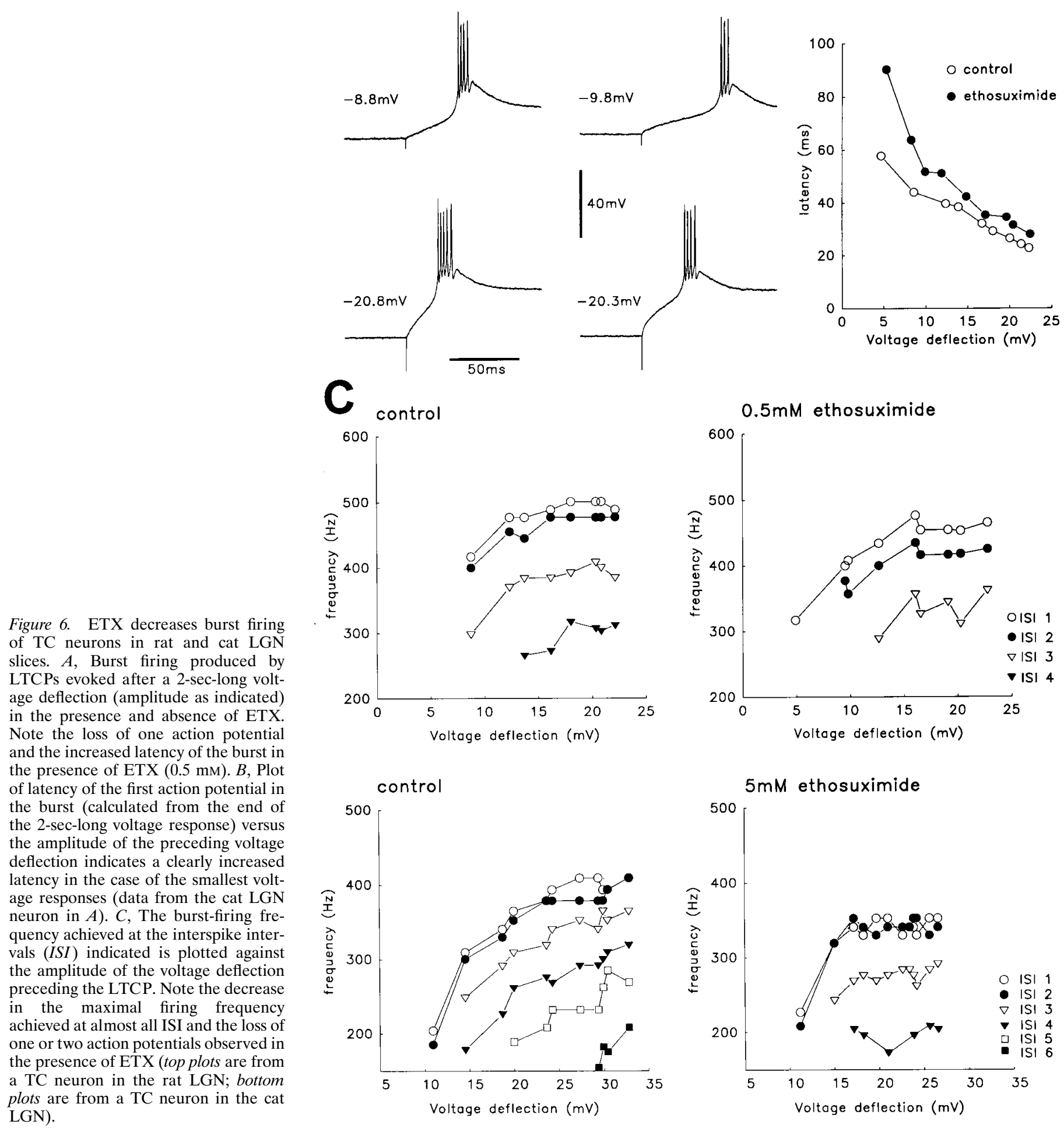

similar age (Coulter et al., 1989b,c, 1990a,b; Huguenard and Prince, 1994).

The lack of action of ETX on $I_{\mathrm{T}}$ in TC and NRT neurons reported here is in sharp contrast to the dose-dependent decrease observed in the original experiments in dissociated neurons (Coulter et al., 1989b,c, 1990a,b) or in slices (Huguenard and Prince, 1994). We have no simple explanation for this discrep- ancy, because similar conditions, species, strains, and ETX concentrations were used in the present investigation and in those studies. Our findings are even more puzzling if one considers that we have used (1) three different rat strains (one of which is genetically prone to absence seizures), (2) TC neurons in two sensory nuclei as well as NRT neurons, and (3) three different sources of ETX. Indeed, ETX from the same batch that was 


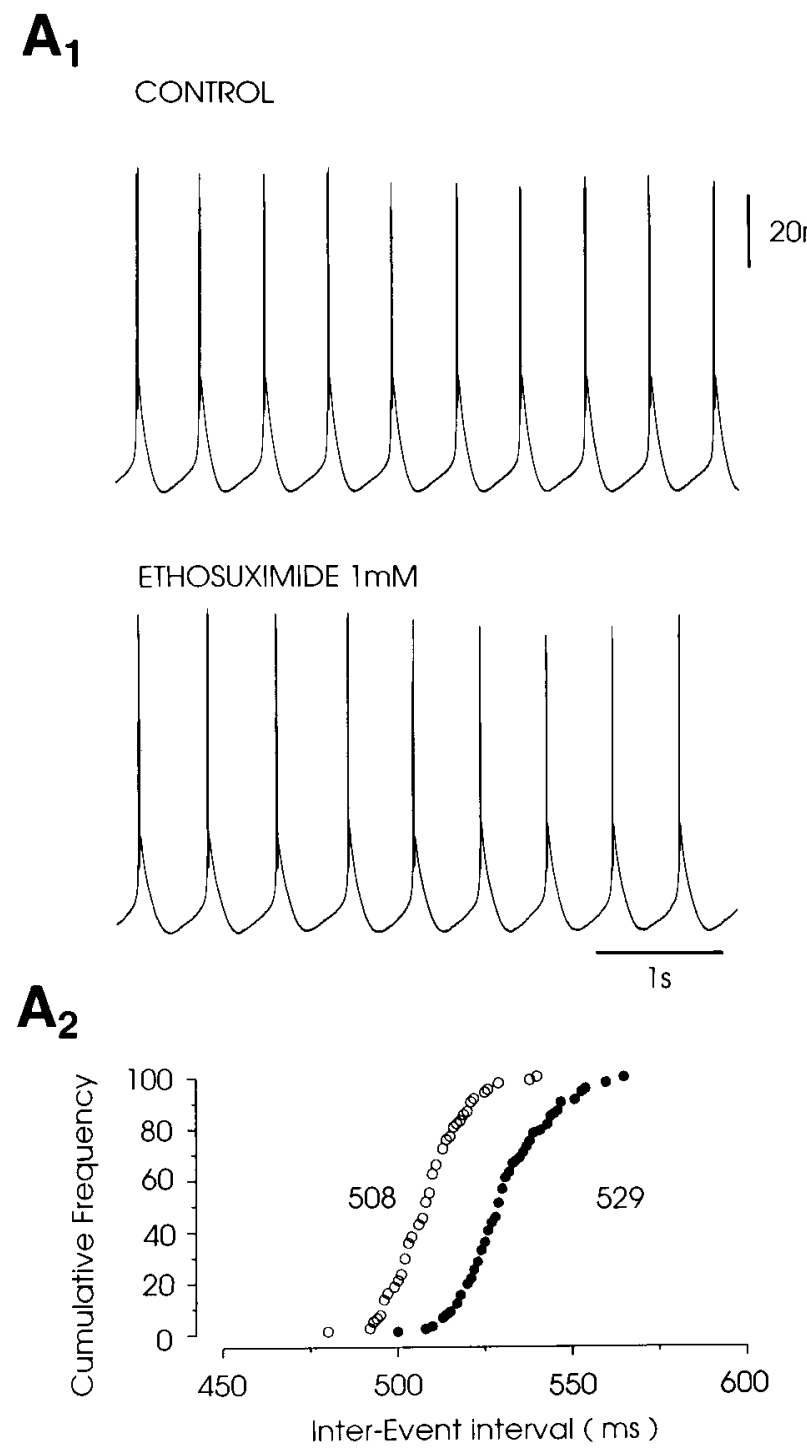

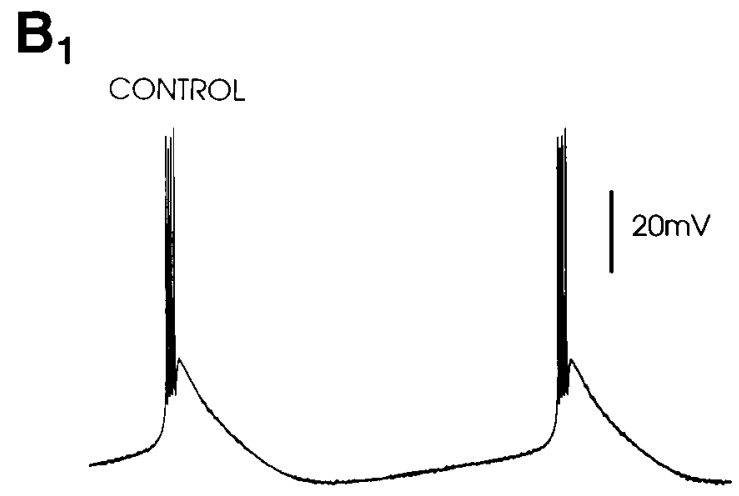

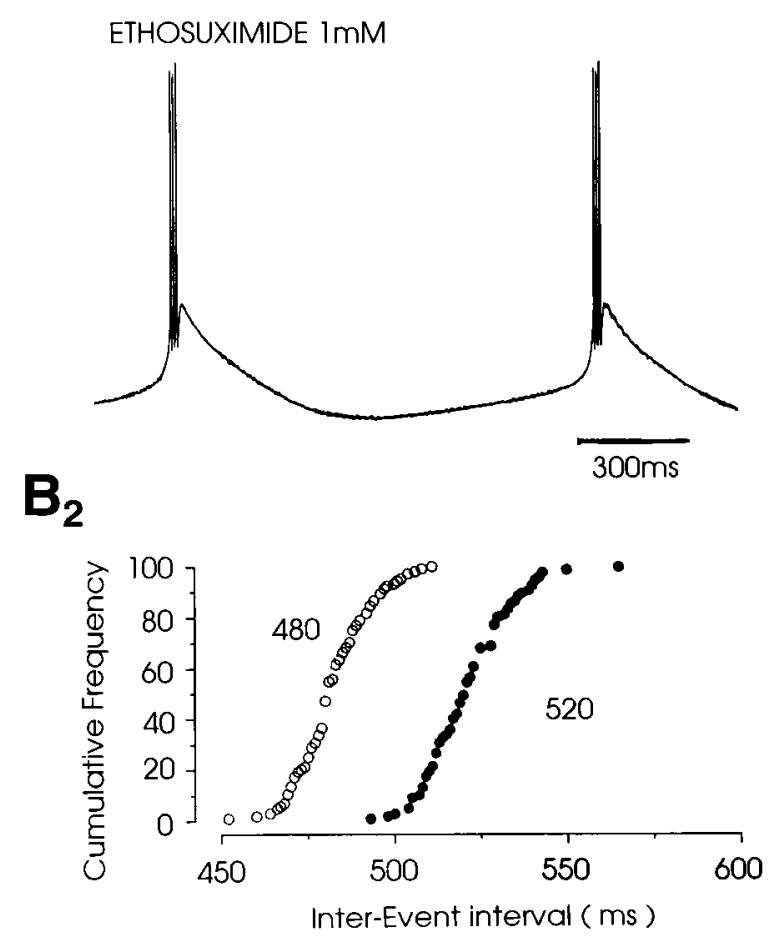

Figure 7. ETX decreases the frequency of $\delta$ oscillation in TC neurons of the cat VB. $A_{1}, B_{1}$, Intracellular voltage traces show, at a different time base, the ETX-induced reduction in the frequency of the pacemaker oscillation recorded from two TC neurons of the cat VB in slices and the loss of one action potential in the burst. $A_{2}, B_{2}$, Cumulative integrative frequency plots of the $\delta$ oscillation (for the same neurons as in $A_{1}$ and $B_{1}$, respectively), recorded at the lowermost level of the voltage region of existence, show the decrease in frequency caused by the application of ETX (1 mM) (open circles, control; closed circles, ETX). The value close to each curve indicates the $50 \%$ frequency probability, which represents the mean interburst interval. DL-APV (0.1 $\mathrm{mm}$ ), CNQX (0.02 mM), MK-801 (0.01 mM), GYKI 52466 (0.1 mM), bicuculline (0.05 mM), and CGP 35348 (0.5 mM) were present in the perfusion medium during these experiments.

ineffective against $I_{\mathrm{T}}$ reduced $I_{\mathrm{K}(\mathrm{Ca})}$ and $I_{\mathrm{NaP}}$ and blocked SWDs when it was injected systemically in GAERS rats.

\section{Effect of ETX on tonic and burst firing}

To the best of our knowledge this study is the first to report an action of ETX on the outward rectification of TC neurons and the consequent increase in tonic firing. Indeed, previous investigations of ETX effects on the repetitive action potential firing of mouse spinal cord neurons in culture and thalamic neurons in slices have found no effect of this anti-absence drug [McLean and MacDonald (1986) and Huguenard and Prince (1994), but see Fig. $3 B_{1}$ in the latter study]. On the other hand, the decrease in the burst firing evoked by LTCPs (i.e., loss of action potentials and reduction in the frequency of the remaining spikes) confirms and enlarges previous observations in TC neurons (Huguenard and Prince, 1994). Because of the lack of action of ETX on low- (this study) and high-threshold $\mathrm{Ca}^{2+}$ currents and on $I_{\mathrm{h}}$ [Coulter et al. (1989b,c, 1990a,b), Huguenard and Prince (1994), and this study], these effects on tonic and burst firing could be explained only by changes in either $\mathrm{Na}^{+}$and/or $\mathrm{K}^{+}$currents. Although no study on the action of ETX on $\mathrm{Na}^{+}$currents of vertebrate neurons is available, very high concentrations of ETX (i.e., 20-50 $\mathrm{mM}$ ) have been shown to decrease the transient $\mathrm{Na}^{+}$current of the squid giant axon in a voltage-independent manner and with no effect on channel gating (Fohlmeister et al., 1984). The present study has shown that therapeutically relevant concentrations of ETX reduce the amplitude of $I_{\mathrm{NaP}}$, whereas $I_{\mathrm{Na}}$ remains unaffected. Because the block of $I_{\mathrm{NaP}}$ by TTX produces effects on the LTCP-mediated burst firing of TC neurons (Parri and Crunelli, 1998) similar to those observed with ETX, we conclude that the reduction of $I_{\mathrm{NaP}}$ by this anti-absence drug is sufficient to explain 
its action on burst firing. Furthermore, the ability of ETX to decrease $I_{\mathrm{NaP}}$ without an effect on $I_{\mathrm{Na}}$ suggests a useful role for this substance in the analysis of the properties and function of $\mathrm{Na}^{+}$channels.

We did not find any effect of ETX on the transient $\mathrm{K}^{+}$current nor on the leakage current, but we did find a decrease in the sustained $\mathrm{K}^{+}$current both in rat and cat TC neurons. Such a reduction had been reported in preliminary form (Coulter et al., 1990b) but did not appear to affect the steady-state voltagecurrent relationship of TC neurons in the VB (Coulter et al., 1990b) (but see Fig. $3 B_{1}$ in Huguenard and Prince, 1994). The lack of action of ETX on the sustained $\mathrm{K}^{+}$current when the perfusion medium contained a low $\mathrm{Ca}^{2+}$ and high $\mathrm{Mg}^{2+}$ concentration supports similar results obtained in the presence of $\mathrm{Cd}^{2+}$ (Coulter et al., 1990b) and suggests an effect on the $I_{\mathrm{K}(\mathrm{Ca})}$ component of the sustained $\mathrm{K}^{+}$current. This reduction of $I_{\mathrm{K}(\mathrm{Ca})}$ explains the increase in apparent input resistance at potentials greater than $-60 \mathrm{mV}$ and the resulting increase in tonic firing. It could be argued that the decrease in $I_{\mathrm{NaP}}$ should counteract the ETX-mediated effect on $I_{\mathrm{K}(\mathrm{Ca})}$. However, the absolute amplitude of $I_{\mathrm{K}(\mathrm{Ca})}$ is larger than that of $I_{\mathrm{NaP}}$, so that a similar percentage in reduction of these two currents by ETX will lead to a smaller net outward current in the membrane potential region close to firing threshold. On the other hand, the more positive threshold of activation of $I_{\mathrm{K}(\mathrm{Ca})}$ (Budde et al., 1992; Huguenard et al., 1991; Huguenard and Prince, 1991) compared with $I_{\mathrm{NaP}}$ (Parri and Crunelli, 1998) ensures that at potentials less than $-70 \mathrm{mV}$ the similar percentage in reduction of these two currents by ETX will lead to a smaller net inward current (i.e., smaller depolarization) that will, in turn, evoke a smaller $I_{\mathrm{T}}$ and LTCP (cf. Parri and Crunelli, 1998).

\section{Implications for ETX action in absence epilepsy}

This study has shown that the overall action of ETX on single rat and cat TC neurons is a complex one that consistently increases tonic firing while dampening their LTCP-mediated burst-firing output, an effect that is also apparent in a physiologically relevant activity such as the $\delta$ oscillation. This ETX-mediated decrease in the burst-firing probability of TC neurons is similar to the action of ETX recorded under whole-cell current-clamp conditions in interconnected TC and NRT neurons (Huguenard and Prince, 1994). Thus, we agree with the interpretation of Huguenard and Prince (1994) that a reduction in burst-firing probability by ETX will lead to a reduction/block of SWDs by decreasing the strength of synchronization within the thalamocortical loop during paroxysmal activity, although this effect on burst firing is not the result of a reduction of $I_{\mathrm{T}}$ by ETX. In this respect it is important to mention that high-frequency burst firing that is not elicited by LTCPs can be generated in TC neurons held at membrane potentials greater than $-60 \mathrm{mV}$ (see Fig. 10 in Turner et al., 1997). Indeed, in the absence of intracellular recordings during SWDs from TC neurons of any of the well established genetic or pharmacological models of absence epilepsy (Snead, 1995; Niedermeyer, 1996), the link between high-frequency firing and LTCPs is based only on indirect evidence from extracellular recordings in the genetic WAG/Rij rat model (Inoue et al., 1993) and the feline penicillin model (Gloor and Fariello, 1988; Avoli et al., 1990). Unfortunately, no data are available on the action of ETX (or other anti-absence medicines) on the $40 \%$ of cat TC neurons that show LTCP-evoked burst firing during spike and wave complexes (Steriade and Contreras, 1995). Similarly, the effect of ETX on the bicuculline-induced oscillation (i.e., rhyth-

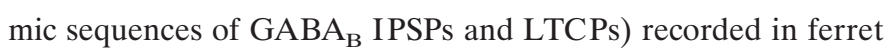
TC neurons in vitro, which has been suggested to resemble the activity that occurs during spike and wave seizures (McCormick and Bal, 1997), has not been investigated. Whatever the precise thalamic mechanisms operating during absence seizures, however, it should be borne in mind that it is the interaction of the different neuronal types within the thalamocortical loop that brings about the characteristic, bilaterally synchronous SWDs (Gloor and Fariello, 1988; Niedermeyer, 1996).

Finally, the present results warrant caution on the "ETX-Ca ${ }^{2+}$ current hypothesis" as the mechanism of action of this antiabsence drug (Coulter, 1989c, 1990b; Huguenard and Prince, 1994) and as a property differentiating between anti-absence drugs and antiepileptics effective against other types of epilepsy (cf. Selzer and Dichter, 1992; McNamara, 1995; Bradley et al., 1996). In addition, the existence of putative differences between the mechanisms of action of ETX and that of relatively newer anti-absence medicines (Rogawski and Porter, 1990; Upton, 1994) should be reconsidered, because members of the latter group (i.e., valproate, lamotrigine) also are known to affect $\mathrm{Na}^{+}$ currents (Selzer and Dichter, 1992; McNamara, 1995) as we now have shown to be the case for ETX.

\section{REFERENCES}

Avoli M, Gloor P, Kostopoulos G, Naquet R (1990) Generalized epilepsy: neurobiological approaches. Boston: Birkhäuser.

Avanzini G, Vergnes M, Spreafico R, Marescaux C (1993) Calciumdependent regulation of genetically determined spike and waves by the reticular thalamic nucleus of rats. Epilepsia 34:1-7.

Bradley WG, Daroff RB, Fenichel GM, Marsden CD (1996) Neurology in clinical practice - principles of diagnosis and management. Boston: Butterworth-Heinemann.

Brown TR, Dreifuss FE, Dyken PR, Goode DJ, Penry JR, Porter RJ, White BG, White PT (1975) Ethosuximide in the treatment of absence (petit mal) seizures. Neurology 25:515-524.

Budde T, Mager R, Pape H-C (1992) Different types of potassium outward current in relay neurons acutely dissociated from the rat lateral geniculate nucleus. Eur J Neurosci 4:708-722.

Coulter DA, Huguenard JR, Prince DA (1989a) Calcium currents in rat thalamocortical relay neurones: kinetic properties of the transient, low-threshold current. J Physiol (Lond) 414:587-604.

Coulter DA, Huguenard JR, Prince DA (1989b) Specific petit mal anticonvulsants reduce calcium currents in thalamic neurons. Neurosci Lett 98:74-78.

Coulter DA, Huguenard JR, Prince DA (1989c) Characterization of ethosuximide reduction of low-threshold calcium current in thalamic neurons. Ann Neurol 25:582-593.

Coulter DA, Huguenard JR, Prince DA (1990a) Differential effects of petit mal anticonvulsants and convulsants on thalamic neurones: calcium current reduction. Br J Pharmacol 100:800-806.

Coulter DA, Huguenard JR, Prince DA (1990b) Cellular actions of petit mal anticonvulsants: implication of thalamic low-threshold calcium current in generation of spike-wave discharge. In: Generalized epilepsy (Avoli M, Gloor P, Kostopoulos G, Naquet R, eds), pp 425-435. Boston: Birkhäuser.

Crunelli V, Lightowler S, Pollard CE (1989) A T-type $\mathrm{Ca}^{2+}$ current underlies low-threshold $\mathrm{Ca}^{2+}$ potentials in cells of the cat and rat lateral geniculate nucleus. J Physiol (Lond) 413:543-561.

Crunelli V, Asprodini E, Guyon A, Turner JP, Vergnes A, Williams SR, Leresche N (1995) On the action of ethosuximide in the rat and cat thalamus. Soc Neurosci Abstr 21:104.

Deschênes M, Paradis M, Roy JP, Steriade M (1984) Electrophysiology of neurons of the lateral thalamic nuclei in cat: resting properties and burst discharges. J Neurophysiol 51:1196-1219.

Erdemli G, Crunelli V (1997) Ethosuximide decreases $\mathrm{Ca}^{2+}$-activated $\mathrm{K}^{+}$currents in rat thalamocortical neurones in vitro. J Physiol (Lond) 501:25P.

Fohlmeister JF, Adelman WJ, Brennan JJ (1984) Excitable channel currents and gating times in the presence of anticonvulsants ethosuximide and valproate. J Pharmacol Exp Ther 230:75-81. 
Gloor P, Fariello G (1988) Generalized epilepsy: some of its cellular mechanisms differ from those of focal epilepsy. Trends Neurosci 11:63-68.

Guyon A, Leresche N (1995) Modulation by different GABA $_{B}$ receptor types of voltage-activated calcium currents in rat thalamocortical neurones. J Physiol (Lond) 485:29-42.

Guyon A, Vergnes M, Leresche N (1993) Thalamic low threshold calcium current in a genetic model of absence epilepsy. NeuroReport 4:1231-1234.

Hernandez-Cruz A, Pape H-C (1989) Identification of low calcium currents in acutely dissociated neurons from the rat lateral geniculate nucleus. J Neurophysiol 61:1270-1283.

Herrington J, Lingle CJ (1992) Kinetic and pharmacological properties of low voltage-activated $\mathrm{Ca}^{2+}$ current in rat clonal (GH3) pituitary cells. J Neurophysiol 68:213-232.

Huguenard JR, Prince DA (1991) Slow inactivation of a TEA-sensitive $\mathrm{K}$ current in acutely isolated rat thalamic relay neurons. J Neurophysiol 66:1316-1328.

Huguenard JR, Prince DA (1992) A novel T-type current underlies prolonged $\mathrm{Ca}^{2+}$-dependent burst firing in GABAergic neurons of rat thalamic reticular nucleus. J Neurosci 12:3804-3817.

Huguenard JR, Prince DA (1994) Intrathalamic rhythmicity studied in vitro: nominal T-current modulation causes robust antioscillatory effects. J Neurosci 14:5485-5502.

Huguenard JR, Coulter DA, Prince DA (1991) A fast transient potassium current in thalamic relay neurons: kinetics of activation and inactivation. J Neurophysiol 66:1304-1315.

Inoue M, Duysens J, Vossen JMH, Coenen AML (1993) Thalamic multiple-unit activity underlying spike-wave discharges in anesthetized rats. Brain Res 612:35-40.

Jahnsen H, Llinás RR (1984) Ionic basis for the electroresponsiveness and oscillatory properties of guinea-pig thalamic neurones in vitro. J Physiol (Lond) 349:227-247.

Kostyuk PG, Molokanova EA, Pronchuk NF, Savchenko AN, Verkhratsky AN (1992) Different action of ethosuximide on low- and highthreshold calcium currents in rat sensory neurons. Neuroscience 51:755-758.

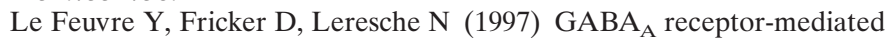
IPSCs in rat thalamic sensory nuclei: patterns of discharge and tonic modulation by $\mathrm{GABA}_{\mathrm{B}}$ receptors. J Physiol (Lond) 502:91-104.

Leresche N, Jassik-Gerschenfeld D, Haby M, Soltesz I, Crunelli V (1990) Pacemaker-like and other types of spontaneous membrane potential oscillations of thalamocortical cells. Neurosci Lett 113:72-77.

Leresche N, Lightowler S, Soltesz I, Jassik-Gerschenfeld D, Crunelli V (1991) Low-frequency oscillatory activities intrinsic to rat and cat thalamocortical cells. J Physiol (Lond) 441:155-174.

Malafosse A, Genton P, Hirsch E, Marescaux C, Broglin D, Bernasconi R (1994) Idiopathic generalized epilepsies. London: Libbey.

Marescaux C, Vergnes M, Depaulis A (1992) Genetic absence epilepsy in rats from Strasbourg-a review. J Neural Transm [Suppl] 35:37-69.

McCormick DA (1991) Functional properties of a slowly inactivating potassium current in guinea pig dorsal lateral geniculate relay neurons. J Neurophysiol 66:1176-1189.

McCormick DA, Bal T (1997) Sleep and arousal: thalamocortical mechanisms. Annu Rev Neurosci 20:185-215.

McLean MJ, MacDonald RL (1986) Sodium valproate, but not ethosuximide, produces use- and voltage-dependent limitation of high frequency repetitive firing of action potentials of mouse central neurons in cell culture. J Pharmacol Exp Ther 237:1001-1011.

McNamara JO (1995) Drugs effective in the therapy of the epilepsies. In: The pharmacological basis of therapeutics (Hardman JG, Goodman Gilman A, Limbird LE, eds), pp 461-486. New York: McGraw-Hill.

Niedermeyer E (1996) Primary (idiopathic) generalized epilepsy and underlying mechanisms. Clin Electroencephalogr 27:1-21.
Parri HR, Crunelli V (1998) Sodium current in rat and cat thalamocortical neurons: role of a non-inactivating component in tonic and burst firing. J Neurosci 18:854-867.

Pfrieger FW, Veselovsky NS, Gottmann K, Lux HD (1992) Pharmacological characterization of calcium currents and synaptic transmission between thalamic neurons in vitro. J Neurosci 12:4347-4357.

Pirchio M, Turner JP, Williams SR, Asprodini E, Crunelli V (1997) Postnatal development of membrane properties and $\delta$ oscillations in thalamocortical neurons of the cat dorsal lateral geniculate nucleus. J Neurosci 17:5428-5444.

Rogawski MA, Porter RJ (1990) Antiepileptic drugs: pharmacological mechanisms and clinical efficacy with consideration of promising developmental stage compounds. Pharmacol Rev 42:223-286.

Roger J, Bureau M, Ferrer-Vidal LO, Daurella LO, Saltarelli A, Genton P (1994) Clinical and electroencephalographic characteristics of idiopathic generalized epilepsies. In: Idiopathic generalized epilepsies: clinical, experimental and genetic aspects (Malafosse A, Genton P, Hirsch E, Marescaux C, Broglin D, Bernasconi R, eds), pp 7-18. London: Libbey.

Sayer RJ, Brown AM, Schwindt PC, Crill WE (1993) Calcium currents in acutely isolated human neocortical neurons. J Neurophysiol 69:1596-1606.

Selzer ME, Dichter MA (1992) Cellular pathophysiology and pharmacology of epilepsy. In: Diseases of the nervous system-clinical neurobiology (Asbury AK, McK hann GM, McDonald WI, eds), pp 916-935. Philadelphia: Saunders.

Sherwin AL (1989) Ethosuximide. Clinical use. In: Antiepileptic drugs (Levy R, Matteson R, Meldrum, Penry JK, Dreifuss FE, eds), pp 685-689. New York: Raven.

Snead III CO (1995) Basic mechanisms of generalized absence seizures. Ann Neurol 37:146-157.

Steriade M, Contreras D (1995) Relations between cortical and thalamic cellular events during transition from sleep patterns to paroxysmal activity. J Neurosci 15:623-642.

Steriade M, Curró Dossi R, Nuñez A (1991) Network modulation of a slow intrinsic oscillation of cat thalamocortical neurons implicated in sleep $\delta$ waves: cortically induced synchronization and brainstem cholinergic suppression. J Neurosci 11:3200-3217.

Suzuki S, Rogawski MA (1989) T-type calcium channels mediate the transition between tonic and phasic firing in thalamic neurons. Proc Natl Acad Sci USA 86:7228-7232.

Thompson SM, Wong RS (1991) Development of calcium current subtypes in isolated rat hippocampal pyramidal cells. J Physiol (Lond) 439:671-689.

Tsakiridou E, Bertollini L, de Curtis M, Avanzini G, Pape H-C (1995) Selective increase in T-type calcium conductance of reticular thalamic neurons in a rat model of absence epilepsy. J Neurosci 15:3110-3117.

Turner JP, Anderson CM, Williams SR, Crunelli V (1997) Morphology and membrane properties of neurones in the cat ventrobasal thalamus in vitro. J Physiol (Lond) 505:707-726.

Upton N (1994) Mechanisms of action of new antiepileptic drugs: rational design and serendipitous findings. Trends Pharmacol Sci 15:456-463.

Williams DA (1953) A study of thalamic and cortical rhythms in petit mal. Brain 76:56-69.

Williams SR, Turner JP, Anderson CM, Crunelli V (1996) Electrophysiological and morphological properties of interneurones in the rat dorsal lateral geniculate nucleus in vitro. J Physiol (Lond) 490:129-147.

Williams SR, Tóth TI, Turner JP, Hughes SW, Crunelli V (1997a) The "window" component of $I_{\mathrm{T}}$ produces input signal amplification and bistability in thalamocortical neurones. J Physiol (Lond) 505:689-705.

Williams SR, Turner JP, Hughes SW, Crunelli V (1997b) On the nature of anomalous rectification in thalamocortical neurones of the ventrobasal thalamus in vitro. J Physiol (Lond) 505:727-747. 